\title{
Implementation of Adaptive Neuro-fuzzy Model to Optimize Operational Process of Multiconfiguration Gas-Turbines
}

\author{
Chao Deng $\left(\mathbb{D},{ }^{1}\right.$ Ahmed N. Abdalla $\mathbb{D}^{2},{ }^{2}$ Thamir K. Ibrahim $\mathbb{D}^{3},{ }^{3}$ MingXin Jiang $\mathbb{D}^{2}{ }^{2}$ \\ Ahmed T. Al-Sammarraie $\mathbb{C}^{4},{ }^{4}$ and Jun $\mathrm{Wu} \mathbb{D}^{1}$ \\ ${ }^{1}$ School of Physics and Electronic Information Eng., Henan Polytechnic University, Jiaozuo, China \\ ${ }^{2}$ Faculty of Electronic Information Eng., Huaiyin Institute of Technology, Huai'an, China \\ ${ }^{3}$ Department of Mechanical Engineering, Tikrit University, Tikrit, Iraq \\ ${ }^{4}$ Department of Mechanical Engineering, University of California, Riverside, CA 92521, USA
}

Correspondence should be addressed to Jun Wu; wujun@hpu.edu.cn

Received 15 January 2020; Accepted 21 April 2020; Published 3 July 2020

Academic Editor: Anna Cimmino

Copyright $(2020$ Chao Deng et al. This is an open access article distributed under the Creative Commons Attribution License, which permits unrestricted use, distribution, and reproduction in any medium, provided the original work is properly cited.

In this article, the adaptive neuro-fuzzy inference system (ANFIS) and multiconfiguration gas-turbines are used to predict the optimal gas-turbine operating parameters. The principle formulations of gas-turbine configurations with various operating conditions are introduced in detail. The effects of different parameters have been analyzed to select the optimum gas-turbine configuration. The adopted ANFIS model has five inputs, namely, isentropic turbine efficiency $\left(T_{\text {eff }}\right)$, isentropic compressor efficiency $\left(C_{\text {eff }}\right)$, ambient temperature $\left(T_{1}\right)$, pressure ratio $\left(r_{p}\right)$, and turbine inlet temperature (TIT), as well as three outputs, fuel consumption, power output, and thermal efficiency. Both actual reported information, from Baiji Gas-Turbines of Iraq, and simulated data were utilized with the ANFIS model. The results show that, at an isentropic compressor efficiency of $100 \%$ and turbine inlet temperature of $1900 \mathrm{~K}$, the peak thermal efficiency amounts to $63 \%$ and $375 \mathrm{MW}$ of power resulted, which was the peak value of the power output. Furthermore, at an isentropic compressor efficiency of $100 \%$ and a pressure ratio of 30 , a peak specific fuel consumption amount of $0.033 \mathrm{~kg} / \mathrm{kWh}$ was obtained. The predicted results reveal that the proposed model determines the operating conditions that strongly influence the performance of the gas-turbine. In addition, the predicted results of the simulated regenerative gas-turbine (RGT) and ANFIS model were satisfactory compared to that of the foregoing Baiji Gas-Turbines.

\section{Introduction}

Energy management, performance analysis, and economic evaluation of a combined heating, cooling, and power system are complicated tasks and often woven into a major project requiring teams of engineers from multidisciplinary backgrounds [1]. The large-scale power and industrial plants have proven the reliability of a combined heat and power (CHP) technology for more than 100 years as the ones that generate electric power and recycle by-product heat from the primary source [2-4]. The conventional implementation of CHP technology is done with large combined cycle gas-turbine (CCGT) systems. Widely successful since the 1950s, the CCGT (also known as cogeneration) systems typically add an unfired waste heat recovery steam generator [5]. The number of available complementary technologies, site specifics, various utility electric rates, and interconnection agreements would only add to the complexity and the cost of the design project [6]. Thus, a preliminary analysis is frequently started with evaluating mathematical models of CHP systems. Mathematical models are not only useful for such decision-making but also invaluable tools to evaluate hypothetical scenarios that would be prohibitively costly or risky to diagnose otherwise [7].

Gas-turbines (GT) are extensively used in several industries which require consumption of considerable power, and this circumstance is often referred to as GT power plants. The GT efficiency is about thermal circulation that has been strongly affected by the overall profitability of electrical energy. The GT plants often must function for extended 
phases even at situations that are not compatible with their planned operating conditions [8]. The relationship between energy utilization and economic growth significantly matters in the current world $[9,10]$. Moreover, improving the thermal efficiency of a power plant includes the joining optimization of disciplines and capacities which are required to achieve operational competitiveness. The design and the efficiency of the plant components identify the combustors, turbine, and compressors [11]. Therefore, understanding the efficiency of GT power plants at such working conditions is crucial, particularly in a deregulated market $[12,13]$.

Gas-turbines are well suited for integrating with CHP technology due to high-quality exhaust heat $[14,15]$, lower initial costs, and shorter construction time compared to other contemporary power generation technologies [16]. The heat coming off the gas-turbine engine is usually converted into steam by the heat recovery steam generator (HRSG) for processing heat or other uses. The conventional application here is to operate the gas-turbine in the combined cycle on base load for maximum thermal efficiency [17]. The simplified physics are captured in the forms of governing equations with the time-dependent conservation laws for each gasturbine component. The dynamic capability of the developed models is intended to be accurate to simulate the transient operating characteristics of components and the fully integrated gas-turbine system without being too computationally intensive. The models are built in MATLAB-Simulink ${ }^{\circledR}$ environment for ease of development and testing control algorithms and strategies.

Computational models are necessary tools in the development and testing of gas-turbine engines. The size and complexity of these models vary from simple zerodimensional curve-fitted expressions to three-dimensional computational fluid dynamics (CFD) simulation packages. The gas-turbine engine in a CHP system is but one of the several important operating cornerstones of a large cogeneration plant, whose overall performance is dictated by the dynamic change of the energy demands from the end-user. As a general rule, computational complexity should be minimized without sacrificing important modeling accuracy to be temporally concise for analysis. The modeling approach is a bottom-up approach in which the fundamental operating unit of a system is developed individually and the parts eventually assemble into an integrated system model [2, 18]. For the gas-turbine, the major components are simulated individually as control volumes described by time-dependent conservation equations. This equipment combination led to increasing pressure losses at the front and rear of the gas-turbine, incurring performance losses at the compressor and turbine section [19]. Furthermore, additional efficiency losses can occur in the gas-turbine due to plant equipment such as an air filtering system, heat recovery steam generator, and selective catalyst reduction.

There are only two methods to examine the performance of the GT plant and its elements at the beginning of the developmental stage, which is either to assess the prototypes of the whole GT energy plant or to consider its primary components. However, these methods are time-consuming to execute [20]. Furthermore, the GT plant works at full load for a significant part of its life. Consequently, it is suggested that the pattern of its performance should be analyzed in detail before it is run. A mathematical model is used with the help of analytical methodology to get the most effective solution for increasing the performance of the plant [21, 22]. Since the sources and consequences of the primary failure of this whole system need to be addressed as efficiently as possible, more research work is required to improve the performance of power plants with the improvement of energy productivity and the reduction in fuel consumption. For this purpose, computerized mathematical modeling of the GT plant will be very useful. Thus, parametric studies on the effect of operating conditions and gas-turbine configurations are required to control those conditions of the system [23, 24]. Lazzaretto and Toffolo [25] developed a physical zero-dimensional relation of a twin-shaft gas-turbine based on experimental data. The study was aimed at simulating the performance and emissions of the variable speed General Electric LM2500-PE Gas-Turbine. Najjar [26] provided a qualitative comparison between the performance of twin-shaft and single-shaft gas-turbines as prime movers of cogeneration plants. This fundamental study reaffirmed the idea that single-shaft gas-turbines are more suitable for a combined cycle plant due to their high efficiency.

Several CHP models still utilize the classical linear programming technique to determine optimal operating strategies, maximize energy management, and minimize the overall cost of energy [27, 28]. In addition, the major components of soft computing, neural networks, genetic algorithms, and fuzzy logic have been also wildly used as successful and capable tools to identify and solve complex mathematical problems [29]. Most notably, the study conducted by Wang et al. [30] has developed a generic algorithm to optimize the configuration of a CHP system for a hotel application. Their model evaluated a comprehensive set of operational parameters including the annual changes in monthly electricity and natural gas prices to deduce the optimal primary energy consumption for the most efficient and highest cost savings [30]. The ANFIS technique was also successfully studied and developed based on the diagnostics of health indices of a $255 \mathrm{MW}$ single-shaft gas-turbine (La Spezia, Italy) $[31,32]$. The analyses mostly focused on optimizing the ANFIS structure, in terms of computational training time, accuracy, and robustness towards measurement uncertainty during simulations. Further, an artificial neural network (ANN) has been proposed to improve the performance and the heat rate of a power plant $[33,34]$.

The present work mainly focuses on the adaptive neural fuzzy system to predict the operating conditions which are associated with the performance enhancement of the gasturbine power plant. Details of the development of powergeneration technologies using simple gas-turbines, complex gas-turbines (regenerative, two-shaft, reheat, and intercooler), and gas-turbine auxiliary systems have comprehensively been investigated, particularly those aimed at enhancing the performance of gas-turbines. The proposed ANFIS model consists of five layers, where the input layer has five neurons representing, namely, isentropic turbine efficiency $\left(T_{\text {eff }}\right)$, isentropic compressor efficiency $\left(C_{\text {eff }}\right)$, ambient 
temperature $\left(T_{1}\right)$, pressure ratio $\left(r_{p}\right)$, and turbine inlet temperature (TIT), and the output layer has three neurons representing fuel consumption, power output, and thermal efficiency. Both the simulated gas-turbine model and ANFIS coding were developed using MATLAB-Simulink ${ }^{\circledR}$ software. Finally, this study validates the employed ANFIS model to single out the parameters associated with the optimal performance of actual operation data for the Baiji Gas-Turbines in Iraq.

\section{Related Work}

2.1. The Power Plant. The Baiji Gas-Turbine power plant is located in Baiji city, Iraq. It has 4 single-cycle gas-turbines. The turbines are SGT5200E Siemens AG (previously known as V94.2). Each one has a design capacity of $150 \mathrm{MW}$ and runs on light fuel oil and heavy fuel oil. The construction work of the power plant was performed by Bharat Heavy Electricals Limited (BHEL) between the years of 2000 and 2003.

2.2. Simple Gas-Turbine Cycle. The gas-turbine is a type of internal combustion engine that converts the heat of combustion into mechanical energy. It does this job by means of first compressing the air in a compressor, then injecting air into a combustor where air and fuel are mixed. Fuel is burned at relatively constant pressure, and heat is released into the hot product gases. As the hot air enters the turbine, it expands, in the process turning the turbine blades and producing mechanical power $[23,24]$. The turbine provides a suitable power to drive the compressor, and whatever power is left is considered as the engine output. The gas-turbine cycle can be represented by a thermodynamic cycle called the Brayton cycle.

Figure 1(a) shows that the overall gas-turbine system mainly consists of four components, i.e., the generator, turbine, combustion chamber, and compressor. The simple gas-turbine diagram shows that the air of the compressor is delivered to the combustion chamber, the fuel increases the compressed air temperature through a combustion process, and the mechanical energy is produced by expanding the hot combustion gases in the turbine and then discharging them to the atmosphere.

The work net of the gas-turbine $\left(W_{\mathrm{Gnet}}\right)$ is expressed as follows [35]:

$$
\begin{aligned}
W_{\mathrm{Gnet}}= & C_{p g} \times \mathrm{TIT} \times \eta_{t}\left(1-\frac{1}{r_{p}^{\left(\gamma_{g}-1\right) / \gamma g}}\right) \\
& -C_{p a} \times T_{1}\left(\frac{r_{p}^{\left(\gamma_{a}-1\right) / \gamma_{a}}}{\eta_{m} \eta_{c}}\right)
\end{aligned}
$$

where $r_{p}$ is the pressure ratio, TIT $\left(T_{3}\right)$ is the turbine inlet temperature, $\eta_{m}$ is the mechanical efficiency, and $\gamma_{g}=1.33$ and $\gamma_{a}=14$.

The specific heat of air $\left(C_{p a}\right)$ is determined as [35]

$$
\begin{aligned}
C_{p a}= & 1.0189 \times 10^{3}-0.1378 T_{a}+1.984 \times 10^{-4} T_{a}^{2} \\
& +4.24 \times 10^{-7} T_{a}^{3}-3.7631 \times 10^{-10} T_{a}^{4},
\end{aligned}
$$

and the specific heat of flue gas $\left(C_{p g}\right)$ is determined as

$$
\begin{aligned}
C_{p g}= & 1.80828-2.31269 \times 10^{-3} T+4.04501 \\
& \times 10^{-6} T^{2}-1.73626 \times 10^{-9} T^{3},
\end{aligned}
$$

where the ambient temperature is measured in Kelvin.

The turbine output power $(P)$ is defined as

$$
P=m_{g} \times W_{\text {Gnet }} \cdot
$$

The turbine exhaust gas mass flow rate $\left(\dot{m}_{g}\right)$ is presented by

$$
\dot{m}_{g}=\dot{m}_{a}+\dot{m}_{f}
$$

where the mass flow rate of inlet air and fuel are $\dot{m}_{a}$ and $\dot{m}_{f}$, respectively. follows:

The specific fuel consumption (SFC) is determined as

$$
\mathrm{SFC}=\frac{3600 f_{r}}{W_{\text {net }}}
$$

where $f_{r}$ is the fuel-to-air ratio.

The additional supplied heat $\left(Q_{\mathrm{add}}\right)$ is determined by the following equation $[(10)]$ :

$$
Q_{\mathrm{add}}=C_{p g} \times\left[\mathrm{TIT}-T_{1} \times\left(1+\frac{r_{p}^{\left(\gamma_{a}-1\right) / \gamma_{a}}-1}{\eta_{c}}\right)\right],
$$

while the overall gas-turbine thermal efficiency $\left(\eta_{t h}\right)$ is expressed as [36]

$$
\eta_{t h}=\frac{W_{\text {Gnet }}}{Q_{\text {add }}}
$$

2.3. Gas-Turbine Configuration Cycle. The efficiency of the simple gas-turbine cycle is low compared to that of steam and diesel turbines. Therefore, different improvements are proposed by many research works which focus on the concept of optimal configuration to enhance the performance of a combined cycle gas-turbine station. The most used methods are discussed in the following section.

2.3.1. Two-Shaft Gas-Turbine. Figure 1(b) shows the process of a two-shaft gas-turbine configuration (TGT) operation. The air is compressed adiabatically, and then the fuel is burned with air through the combustion chamber to the maximum cycle temperature which occurs at state 3 . The exhaust gases produced by the combustion process are used to drive the compressor $[37,38]$. The low gas-turbine exhaust gases temperature $\left(T_{5}\right)$ is defined as

$$
T_{5}=T_{4}\left[1-\eta_{t}\left(1-\frac{T_{5 s}}{T_{4}}\right)\right]
$$

where $T_{5 s}$ is the exit low-pressure turbine temperature. 


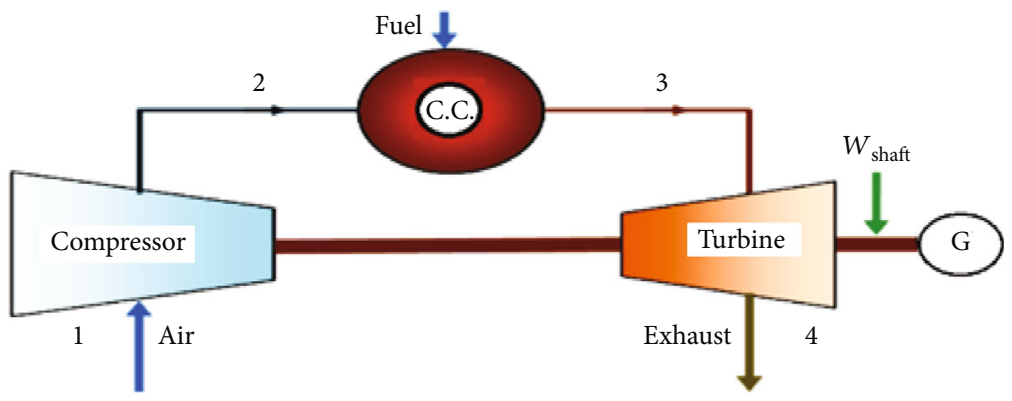

(a) SGT cycle

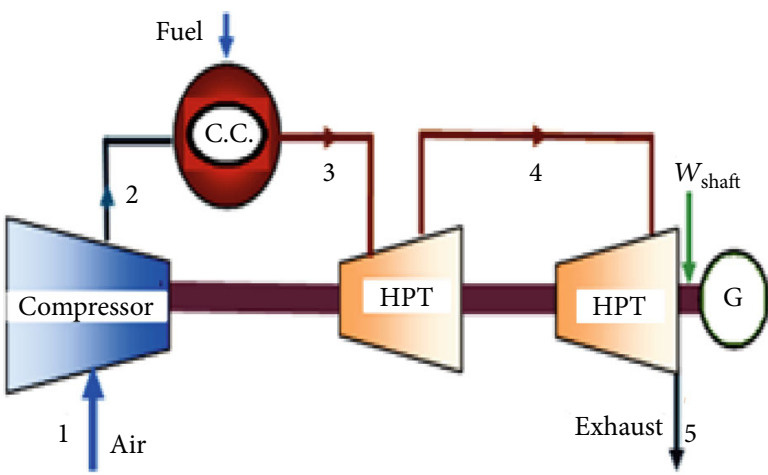

(b) TGT cycle

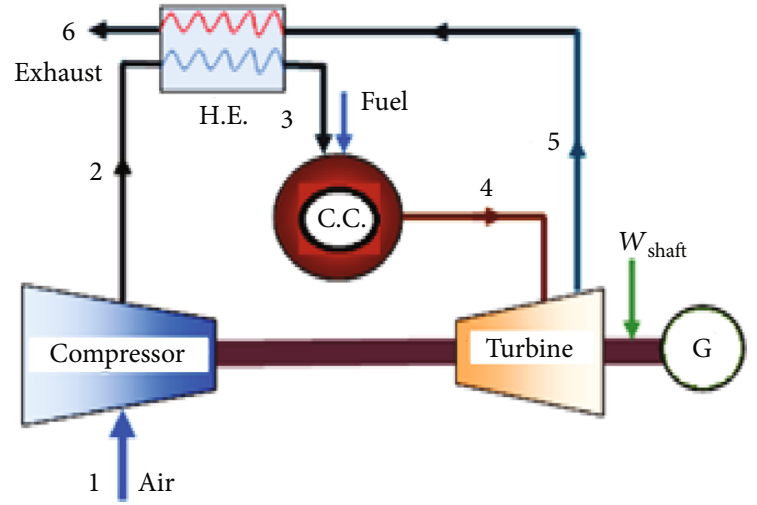

(d) RGT cycle

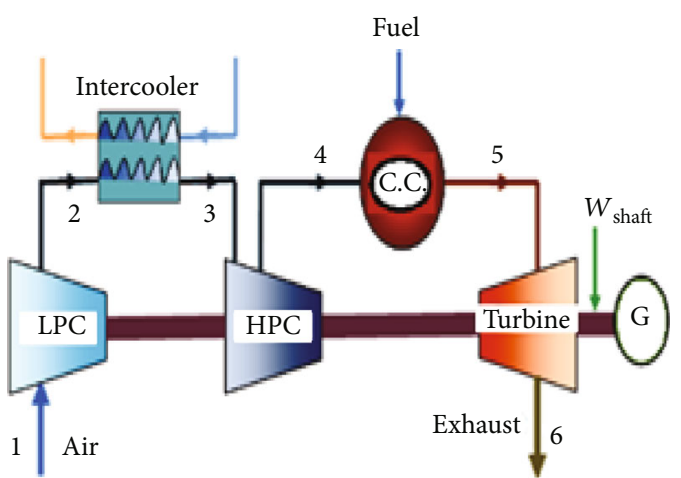

(c) IGT cycle

Figure 1: Schematic diagram of different gas-turbine cycles.

The work net is expressed as

$$
W_{\text {net }}=C_{p g}\left(T_{4}-T_{5}\right)
$$

and the heat addition $\left(Q_{\text {add }}\right)$ is expressed as

$$
Q_{\mathrm{add}}=C_{p g}\left(\mathrm{TIT}-T_{4}\right)
$$

2.3.2. Intercooled Gas-Turbine (IGT). Intercooling is important to reduce the power consumption of air compression and maintain the second stage compressor inlet temperature as low as possible. Figure 1(c) shows a single-shaft gasturbine plant with intercooler. In this cycle, the first-stage compressor, the compressed air enters and is cooled in the intercooler. The second stage compressor compresses the cooled air for a specific pressure rate and then transmits it to the combustion chamber to a maximum permissible temperature [39]. The cycle work net output is directly proportional to the turbine temperature drop. The work net is expressed as follows [40]:

$$
\begin{aligned}
W_{\text {Gnet }}= & C_{p g} \operatorname{TIT} \cdot\left[\frac{\eta_{t}}{\eta_{m}}\left(1-\frac{1}{\left(r_{p}^{2}\right)^{\left(\gamma_{a}-1\right) / \gamma_{a}}}\right)\right] \\
& -C_{p a} T_{1}\left(\frac{r_{p}^{\left(\gamma_{a}-1\right) / \gamma_{a}-1}}{\eta_{m} \eta_{c}}\right)\left[2+(1-x)\left(\frac{r_{p}\left(\gamma_{a}-1\right) / \gamma_{a}-1}{\eta_{c}}\right)\right],
\end{aligned}
$$


In the combustion chamber, the heat absorbed by air is equal to the fuel-supplied heat. The fuel-supplied heat is determined by the following equation [41]:

$$
\begin{aligned}
Q_{\mathrm{add}}= & C_{p g}\left[\operatorname{TIT}-T_{1}+T_{2}\left(\frac{r_{p}\left(\gamma_{a}-1\right) / \gamma_{a}-1}{\eta_{c}}\right)\right. \\
& \left.\cdot\left((2-x)+(1-x)\left(\frac{r_{p}\left(\gamma_{a}-1\right) / \gamma_{a}-1}{\eta_{c}}\right)\right)\right] .
\end{aligned}
$$

2.3.3. Regenerative Gas-Turbine. The single-shaft gasturbine produces the necessary power required to run the compressor. Figure $1(\mathrm{~d})$ shows the regenerative gasturbine (RGT) cycle where the compressed air enters into a regenerator to be heated by the exhaust gases coming from the turbine. Then, the air is additionally preheated to a maximum permissible temperature in the combustion chamber [21]. The work net can be defined as follows:

$$
\begin{aligned}
W_{\text {Gnet }}= & \frac{C_{p g} \times \operatorname{TIT} \times \eta_{t}}{\eta_{m}}\left(1-\frac{1}{r_{p}^{\left(\gamma_{g}-1\right) / \gamma_{g}}}\right) \\
& -C_{p a} T_{1}\left(\frac{r_{p}^{\left(\gamma_{a}-1\right) / \gamma_{a}}}{\eta_{m} \eta_{c}}\right) .
\end{aligned}
$$

In the combustion chamber, the fuel-supplied heat is equal to the absorbed air heat, which can be expressed as

$$
\begin{aligned}
Q_{\mathrm{add}}= & C_{p g} \times\left[\mathrm{TIT}-T_{1}(1-\varepsilon) \times\left(1+\left(\frac{r_{p}\left(\gamma_{a}-1\right) / \gamma_{a}-1}{\eta_{c}}\right)\right)\right. \\
& \left.-\varepsilon \times \operatorname{TIT} \times\left[1-\eta_{t}\left(1-\frac{1}{r_{p}\left(\gamma_{a}-1\right) / \gamma_{a}}\right)\right]\right] .
\end{aligned}
$$

2.3.4. Reheat Gas-Turbine. The principle of improving the performance of the SGT cycle can be implemented by means of reheating the gases at some intermediate points to the maximum cycle temperature [40]. Figure 1(e) depicts a reheat gas-turbine (HGT) cycle. For the isentropic process, the work of the gas-turbine is expressed as

$$
W_{\text {Gnet }}=C_{p g}\left(\mathrm{TIT}-T_{6}\right) \text {, }
$$

where the turbine inlet temperature is TIT $=T_{3}=T_{5}$, and $T_{4}$ is the HP turbine outlet temperature.

The exhaust gas temperature from the LP gas-turbine is obtained by

$$
T_{6}=\operatorname{TIT}\left[1-\eta_{t}\left(1-\frac{\mathrm{TIT}}{\left(r_{p}^{\left(\gamma_{g}-1\right) / \gamma_{g}} \times T_{4}\right)}\right)\right] a=1 \text {, }
$$

and the heat supplied for HGT is expressed as

$$
Q_{\mathrm{add}}=C_{p g}\left[\left(\mathrm{TIT}-T_{2}\right)+\left(T I T-T_{4}\right)\right]
$$

\section{Proposed Method}

The fundamental mechanism for the Sugeno model and its corresponding ANFIS architecture is illustrated in Figure 2 [42]. The ANFIS model consists of five layers and each layer with a number of the node. Figure 2 shows the general adaptive model that has two inputs $x$ and $y$ and one output $f$.

Layer 1 is adaptive nodes producing linguistic-label membership grades as expressed by

$$
O_{1, i}=\mu_{A i}(x)=\frac{1}{1+\left|\left(x-c_{i}\right) / a_{i}\right|^{2 b_{i}}},
$$

where the input node is presented by $x$ and $y$, the layer output node is presented by $O_{1, i}$, and the fuzzy membership function set $=\left\{a_{1}, a_{2}, b_{1}, b_{2}\right\}$ related to the node [43].

Layer 2 presents the fixed nodes of all the input indications which are determined by [43]

$$
O_{2, i}=W_{i}=\mu_{A i}(x) \mu_{B i}(y), \quad i=1,2 .
$$

Layer 3 presents the normalized firing strengths in which each node is a fixed rule labeled $N$ node output which is determined by

$$
O_{3, i}=\bar{W}_{t}=\frac{W_{i}}{W_{1}+W_{2}}, \quad i=1,2,
$$

where $\bar{W}_{i}$ is the normalized firing strength.

In layer 4 , the output rule is determined for each node by

$$
O_{4, i}=\bar{W}_{i} f_{i}=\bar{W}_{i}\left(p_{i} x+q_{i} y+r_{i}\right)
$$

where $\left\{p_{i}, q_{i}, r_{i}\right\}$ presented the resultant parameter set of the node.

Layer 5 is the sum of the node outputs of the overall ANFIS output determined by [42]

$$
O_{5, i}=\sum_{i} \bar{W}_{i} f_{i}=\frac{\sum_{i} W_{i} f_{i}}{\sum_{i} W_{i}} .
$$

Figure 3 exhibits the proposed ANFIS model which has five inputs, namely, isentropic turbine efficiency $\left(T_{\text {eff }}\right)$, isentropic compressor efficiency $\left(C_{\text {eff }}\right)$, ambient temperature $\left(T_{1}\right)$, pressure ratio $\left(r_{p}\right)$, and turbine inlet temperature (TIT), and three single outputs, namely, thermal efficiency, power output, and fuel consumption.

\section{Results and Discussion}

4.1. Modeling and Simulation. This section investigates the performance of gas-turbine configurations based on various operating conditions such as isentropic turbine efficiency $\left(T_{\text {eff }}\right)$, ambient temperature $\left(T_{1}\right)$, isentropic compressor 


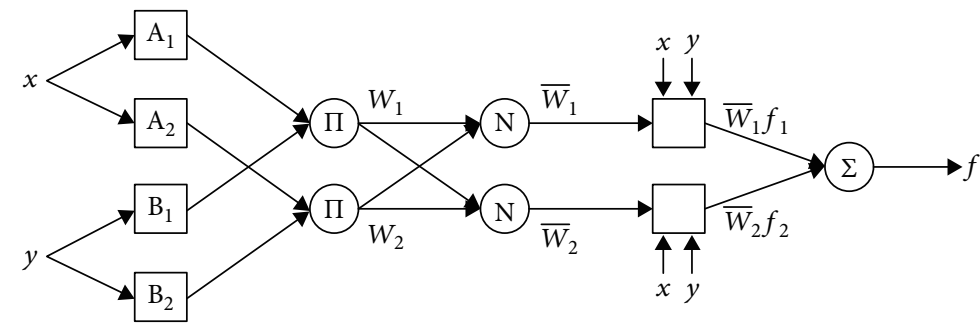

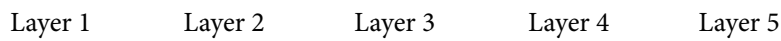

(a)

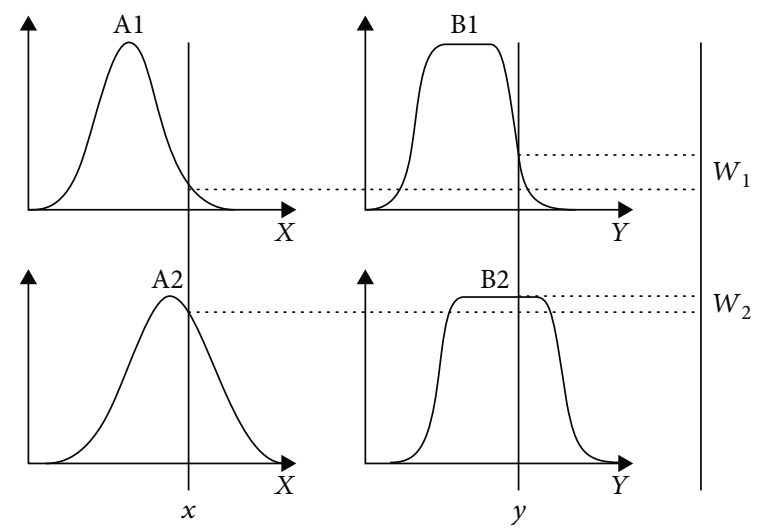

$$
f_{1}=p_{1} x+q_{1} y+r_{1}
$$

$\Longrightarrow f=\frac{W_{1} f_{1}+W_{2} f_{2}}{W_{1}+W_{2}}$

$=\bar{W}_{1} f_{1}+\bar{W}_{2} f_{2}$

(b)

Figure 2: The basic equivalent architecture of ANFIS (a) two-input first-order (b) Sugeno fuzzy model with two rules.

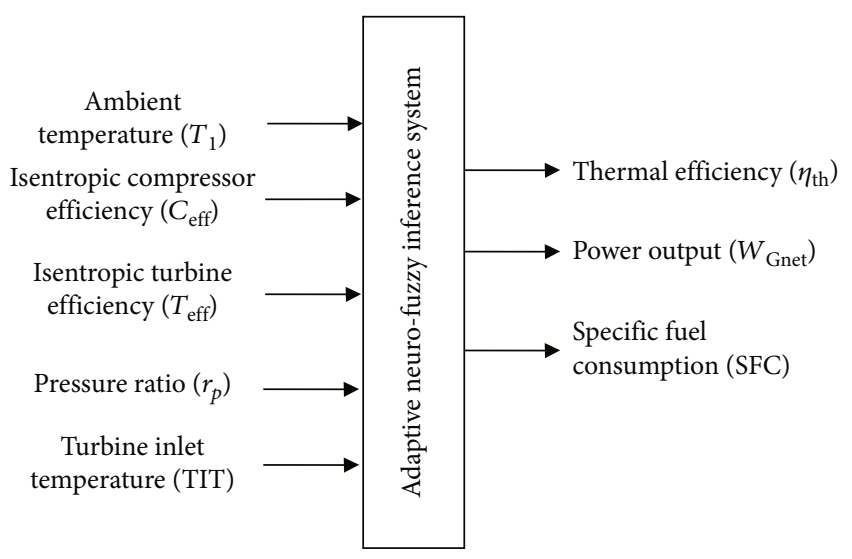

FIGURE 3: Proposed ANFIS architecture for equivalent GT model.

efficiency $\left(C_{\text {eff }}\right)$, turbine inlet temperature (TIT), and pressure ratio $\left(r_{p}\right)$. A comparison between the simulated thermal efficiency of the simple GT and the Boyce model [44] is demonstrated in Figure 4. This figure shows an increase in thermal efficiency with the increase in pressure ratio. Compared to the Boyce model of the simple GT, we can confirm that our simulation results are adequate. This is because of an incomplete combustion caused by the usage of fuel oil instead of natural gas in the Baiji plant, thus decreasing the thermal efficiency of the GT power plant. Furthermore, the compressor is much more intolerant to dirt build up in the inlet air filter and on the compressor blades which creates large drops in the cycle efficiency and performance of the
Baiji GT power plant. Furthermore, a comparative analysis of the simulated thermal efficiency of the regenerative GT and the Bassily model [45] together with the effect of different values of the pressure ratio and TIT is shown in Figure 5. It is obvious from this figure that there is an increase in thermal efficiency until the pressure ratio reaches 6 . The thermal efficiency starts to decrease with the increase in the pressure ratio after the compression value reaches 7 due to the rise in the compressor outlet temperature as a result of the increased pressure ratio. Therefore, the thermal efficiency was reduced due to the reduction in the heat exchange between the air and the flue gases in the regenerative gasturbine [45]. It is also noticed that increasing the TIT has led to an increase in thermal efficiency. Compared to the Bassily model of the regenerative GT, our simulation results are adequate, as well.

The effect of pressure ratio on the performance of the GT plants is exhibited in Figure 6. The impact of the pressure ratio on the temperature of the exhaust gases from different configurations of the GT is shown in Figure 6(b). It is evident that the decrease in the temperature of the exhaust gases for all the models, except the regenerative GT model, is increased from 590 to $796 \mathrm{~K}$, as an increase in the pressure ratio. Also, when the pressure ratio increases according to the configuration of the GT for other models, so does the exhaust temperature decreases about 220 to $400 \mathrm{~K}$. The heat recovered from the flue gases to increase the temperature of the air entering the combustion chamber leads to a reduction in the temperature of the exhaust with the regenerative GT model [45]. The two-shaft GT model causes a high exhaust temperature, 


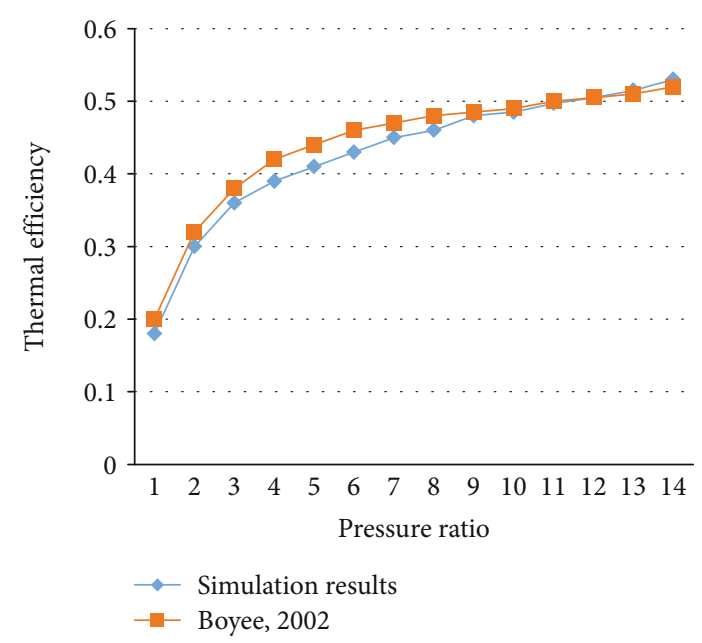

FIGURE 4: The relation of thermal efficiency and pressure ratio of the simple GT and Boyce model.

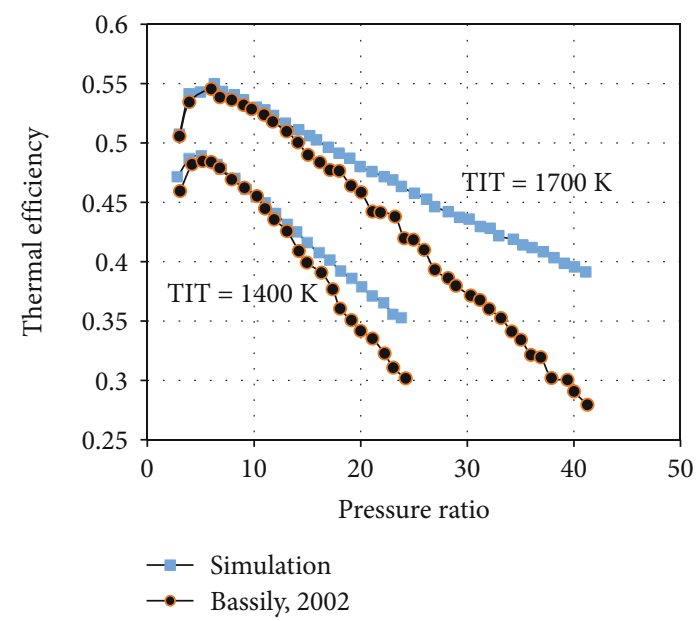

FIGURE 5: The relation of thermal efficiency and pressure ratio of the regenerative gas-turbine and Bassily model.

owing to the presence of the two-shaft GT with one shaft that drives the compressor, while the other drives the generator. It should be mentioned that the increase in the exhaust gas temperature stems from the decrease in the total isentropic turbine efficiency and the work of the turbines [26].

The effect of the pressure ratio on the thermal efficiency of the GT plants is displayed in Figure 6(a). In the case of all the configurations, except the regenerative GT, increasing the compressor ratio creates a linear increase in the thermal efficiency. On the other hand, the thermal efficiency of the regenerative GT rises up to $46.5 \%$ at a pressure ratio value of 7. Afterward, it starts to decrease till $37.3 \%$ when the pressure ratio soars to 30 . More waste heat can be recovered due to the low outlet temperature of the compressor and the low pressure ratio. Less waste heat needs to be retrieved as the high outlet temperature was obtained at a high pressure ratio [46]. As a consequence, there is an increase in the thermal efficiency of the pressure ratio for other configurations. Com- pared to the lower pressure ratio, the higher pressure ratio has a significant variation in the thermal efficiency of the GT.

Moreover, Figure 6(a) shows the effect of the pressure ratio on the fuel consumption for the different studied configurations. At a pressure ratio of 7 , the specific fuel consumption has a minimum value $(0.159 \mathrm{~kg} / \mathrm{kWh})$ in the regenerative GT. This value starts to increase after passing the value of the pressure ratio. In the case of the other configurations, the specific fuel consumption always decreases with the increment in the pressure ratio. In comparison with the lower pressure ratio, the deviation of the specific fuel consumption is higher at the higher pressure ratio. When the pressure ratio increases from 3 to 30 for all configurations, except the regenerative one, the specific fuel consumption decreases (about $0.32 \mathrm{~kg} / \mathrm{kWh}$ to $0.17 \mathrm{~kg} / \mathrm{kWh}$ ).

As indicated in Figure 6(b), this is a result of the decrease in the exhaust temperature with the increase in the pressure ratio. In addition, the variation of GT cycles' output power with the pressure ratio is shown in Figure 6(a). As is evident, increasing the pressure ratio leads to an increase in the output power depending on the configuration of the GT. However, it is noticed that the higher pressure ratio is significant on the output power variation. Due to the burning of more fuel in the additional combustion chamber, the higher output power is obtained in the reheated GT configuration [47]. It can be seen that the lower pressure ratio was insignificant on the output power.

The effect of ambient temperature on the performance of the GT plants is depicted in Figure 7. The variation of the exhaust temperature of the GT power plants with the effect of the ambient temperature is demonstrated in Figure 7(b). In the case of all the configurations, except the regenerative GT, the increase in the ambient temperature leads to a gradual rise in the exhaust temperature by about $10 \mathrm{~K}$. The regeneration applied to recover heat from the flue gases and increase the air temperature entering the combustion chamber is the main reason behind it. Therefore, for the RGT compared to the other GT configurations, the temperatures of the exhaust gases are increased with increase of the ambient temperature $[13,48]$. The lowest exhaust temperature of about $655 \mathrm{~K}$ is obtained in the regenerative GT, while the highest temperature of about $1200 \mathrm{~K}$ is obtained in the two-shaft GT. Furthermore, the effect of ambient temperature on the thermal efficiency of the GT cycle for different configurations is shown in Figure 7(a). The rising ambient temperature causes a reduction in thermal efficiency. Increasing the ambient temperatures also results in the increased losses of the exhaust gases, which is also a reason for the reduction of the thermal efficiency $[49,50]$. The maximum thermal efficiency for the GT configurations is obtained at an ambient temperature of $273 \mathrm{~K}$ with the regenerative GT configuration, while at an ambient temperature of $327 \mathrm{~K}$, a minimum thermal efficiency of $33 \%$ for the intercooler gas-turbine (IGT) configuration is observed. The work of the compressor increases as the ambient temperature increases. Therefore, there is a reduction in the thermal efficiency of all the configurations. The design of the compressor of the GT is such that it maintains a constant air volume, while the mass is reduced with the increase in the ambient 


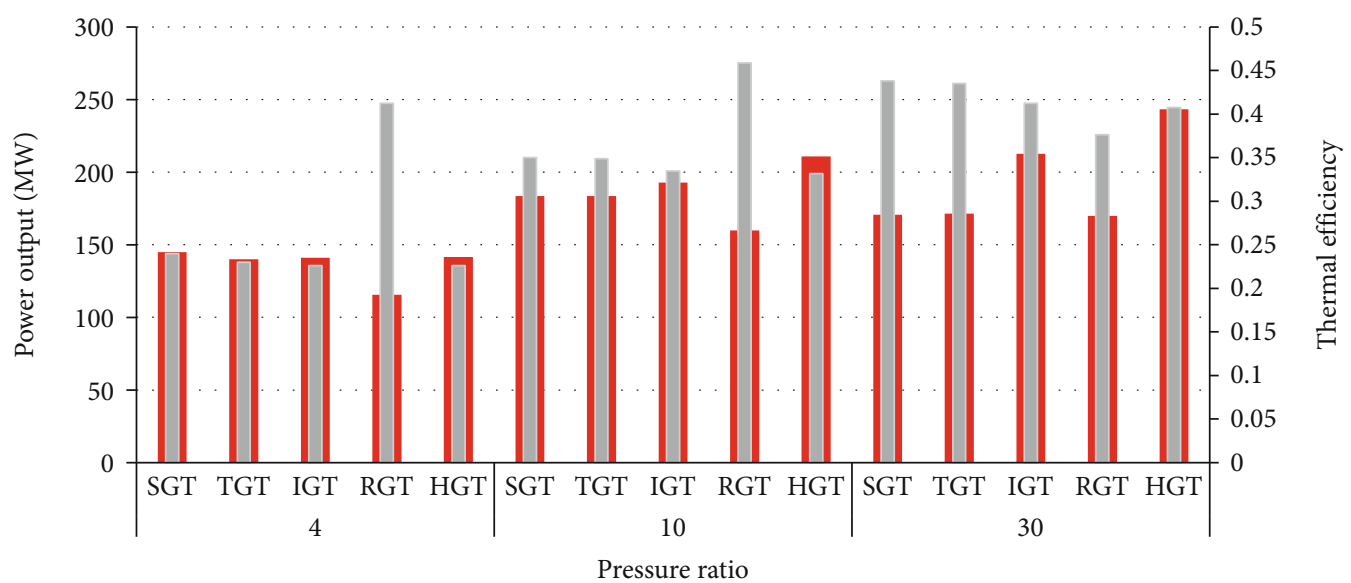

(a)

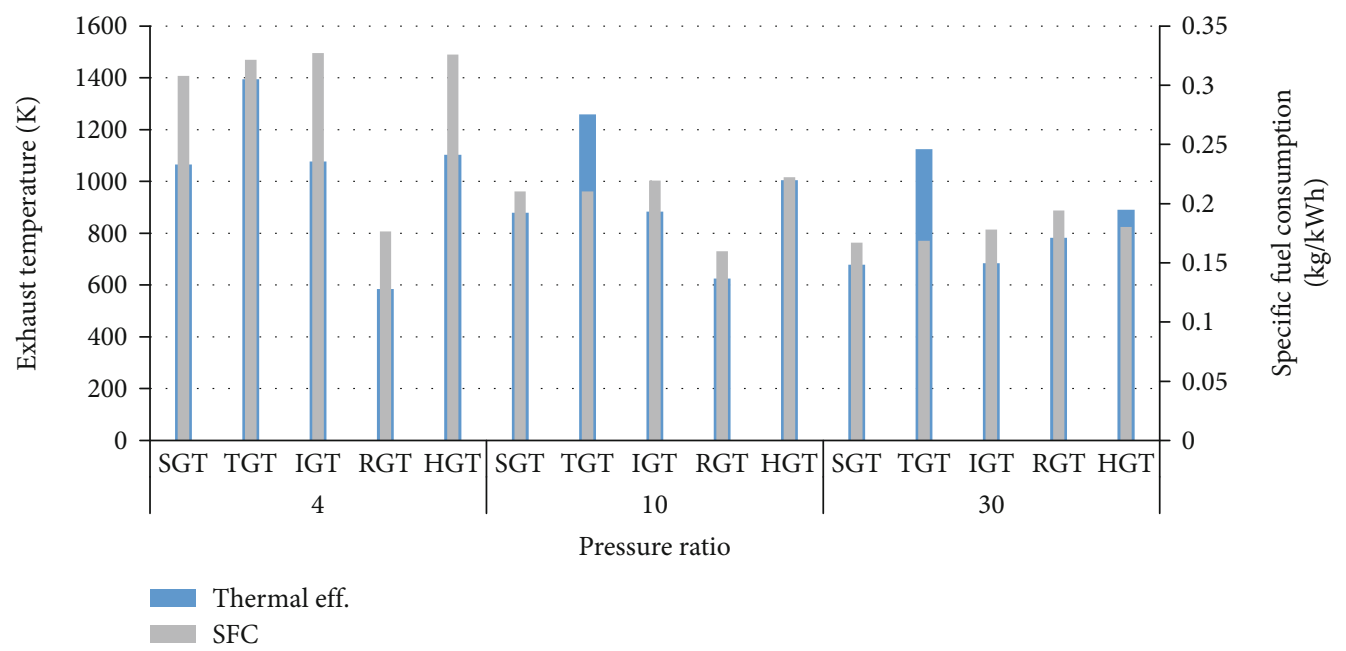

(b)

FIGURE 6: The impact of pressure ratio on the performance of the gas-turbine.

temperature [51]. The mass flow is reduced to maintain the same volumetric flow, which leads to a reduction in the output power of the GT and an increase in the temperature at the inlet of the combustion chamber $[26,51]$. The GT thermal efficiency eventually decreases as there is a decrease in the burning fuel and the TIT. Figure 7(b) indicates the variation of the specific fuel consumption of the GT power plant with the effect of the ambient temperature. The specific fuel consumption and the ambient temperature are directly proportional to each other [52]. For all the configurations of the GT, the specific fuel consumption increases with the increase in the ambient temperature. In the presence of the regenerative GT configuration at an ambient temperature of $273 \mathrm{~K}$, the lowest specific fuel consumption occurs at $0.156 \mathrm{~kg} / \mathrm{kWh}$. While with the reheated GT configuration at ambient temperature of $327 \mathrm{~K}$, the highest specific fuel consumption occurs at $0.223 \mathrm{~kg} / \mathrm{kWh}$.

The predicted output power of the GT configurations with the actual data from the Baiji GT power plant versus the ambient temperature is shown in Figure 8. For all the configurations, the output power has been observed to decrease with the increase in the ambient temperature. It is observed that, at any ambient temperature, the lowest and highest output powers obtained are for the regenerative and reheated GT configurations, respectively. Likewise, for all the configurations, except the intercooler GT configuration, a decrease in the output power by $296 \mathrm{MW}$ is observed when the ambient temperatures increased from $273 \mathrm{~K}$ to $327 \mathrm{~K}$. The rise in exhaust temperatures is the main reason behind this behavior [53]. Moreover, compared to the output power data of the Baiji GT power plant, enhanced output power has been obtained utilizing the studied GT configurations. The Baiji GT plant uses the fuel oil, which when burned creates a loss in the output power due to the incomplete combustion. On the contrary, the models proposed for the GT plant are designed to work on complete combustion of the natural gas. The effect of the TIT on the performance of the GT plants is shown in Figure 9. The effect of the TIT on the exhaust temperature of the GT plants is displayed in Figure 9(a). It observed that increasing the TIT causes a rise in exhaust 


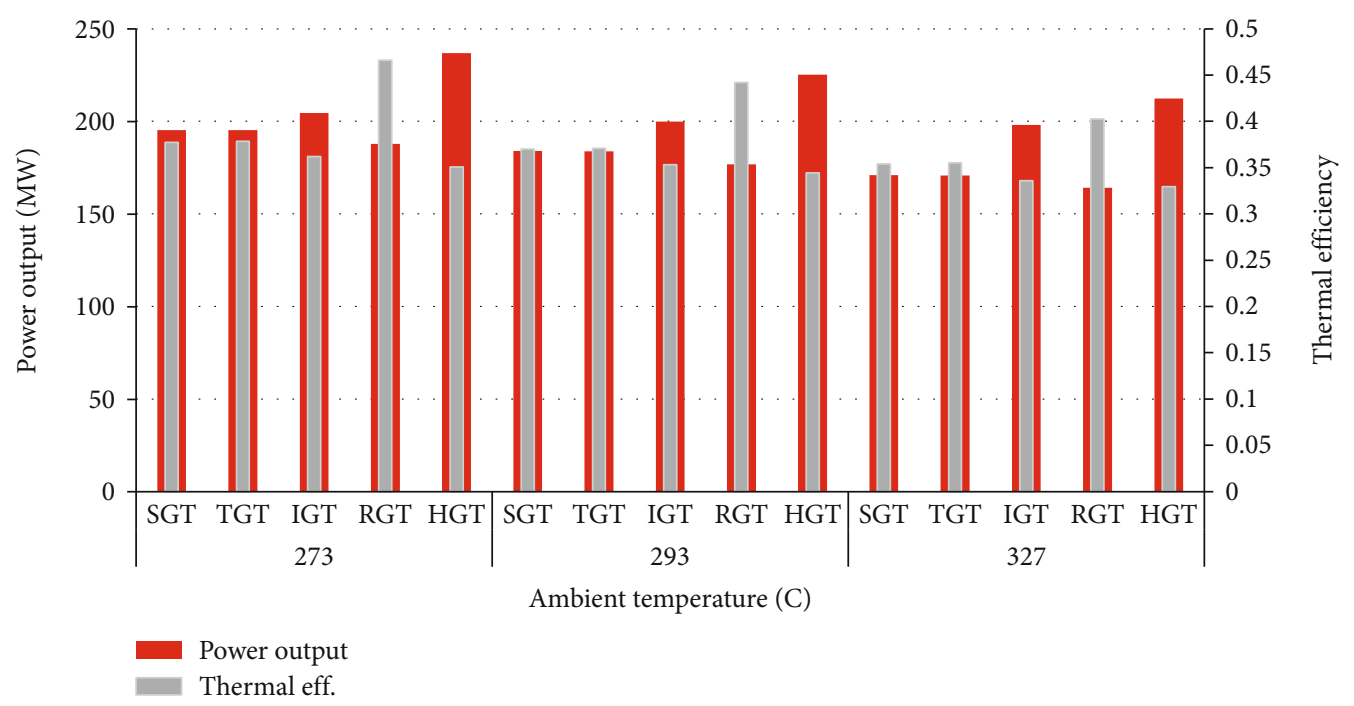

(a)

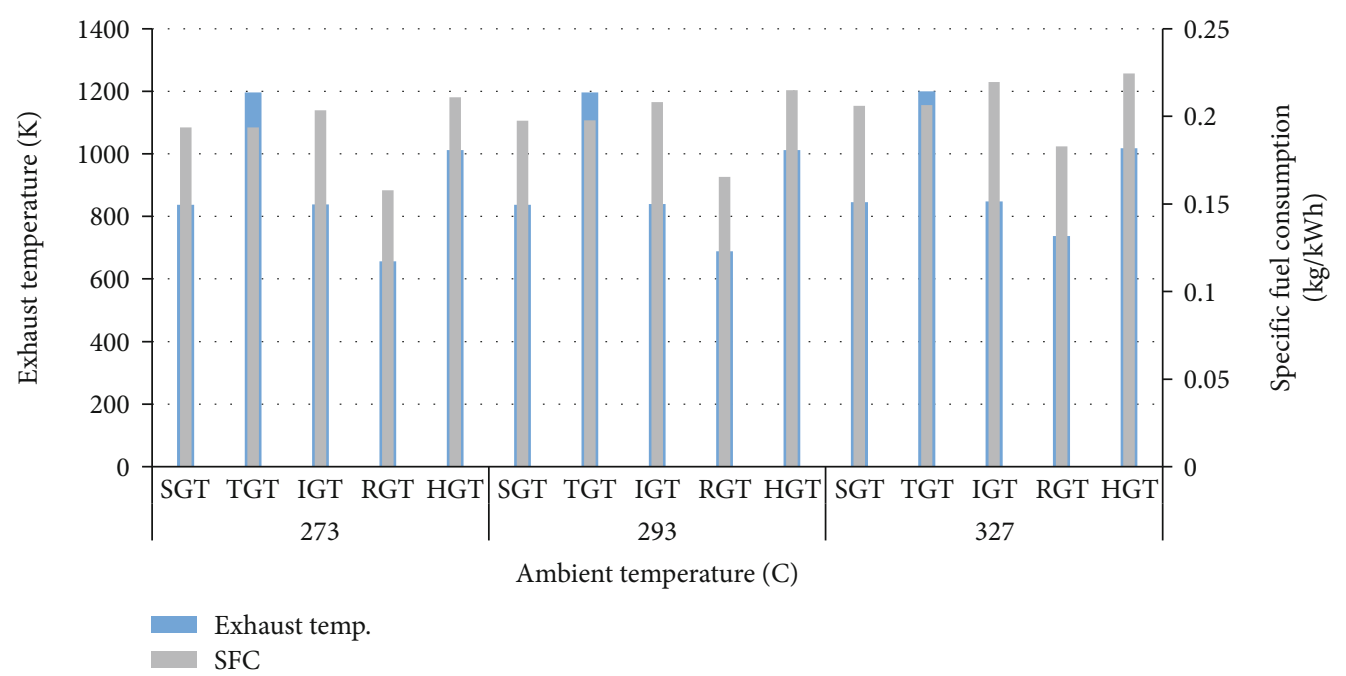

(b)

FIgURE 7: The impact of ambient temperature $\left({ }^{\circ} \mathrm{C}\right)$ on the performance of the gas-turbine.

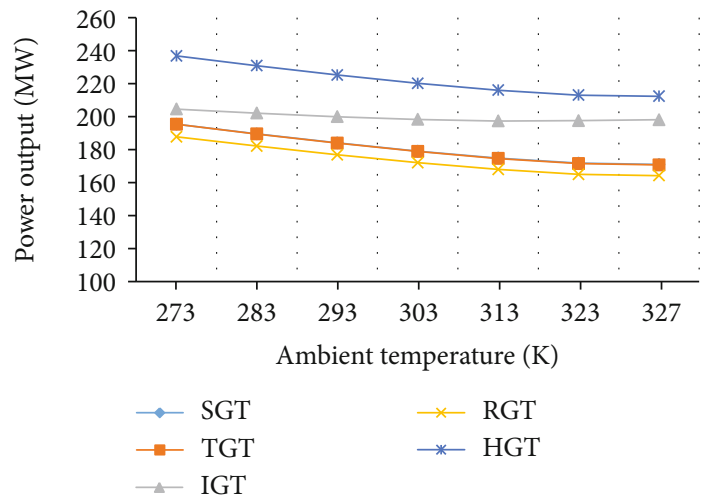

Figure 8: The relation between the output power and the ambient temperature for the predicted results and the actual data from the Baiji Gas-Turbine power plant. temperature which means that enough heat is supplied by the high TIT to the power turbine, which is then able to produce higher exhaust gases and work net from the GT [54]. Therefore, when the TIT increases from 1100 to $1900 \mathrm{~K}$ for all configurations, except for the regenerative GT, the exhaust temperature of the GT also increases by about $700 \mathrm{~K}$. In fact, there is an increase of $150 \mathrm{~K}$ in the exhaust temperature of the regenerative model though. At low TIT, there is a minor variation in the exhaust temperature, while at the higher TIT, the exhaust temperature is significant for all the GT configurations. The variation of the thermal efficiency against the TIT for various configurations of the GT is shown in Figure 9(b). It is observed that with the increase in the TIT, there is an increase in thermal efficiency. There is a nominal deviation in the thermal efficiency at the lower TIT, while the deviation is significant at the higher TIT. This occurs owing to the increased work that the GT cycle has to do [13].

Therefore, to increase the thermal efficiency of the GT, the TIT becomes a very critical factor. Except for the 


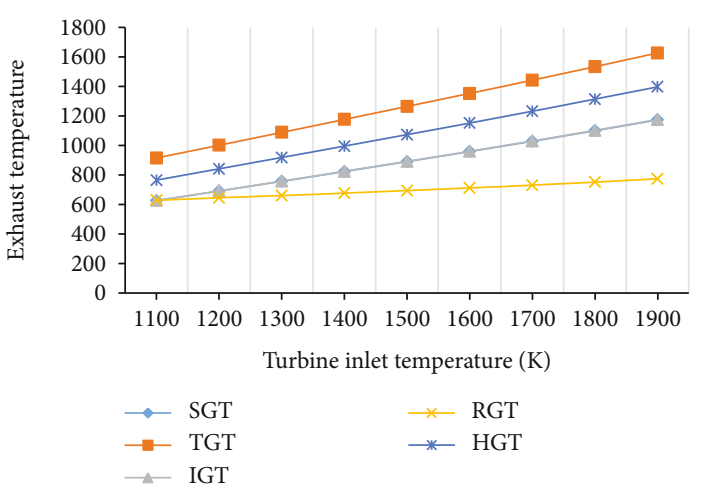

(a) Exhaust temperature

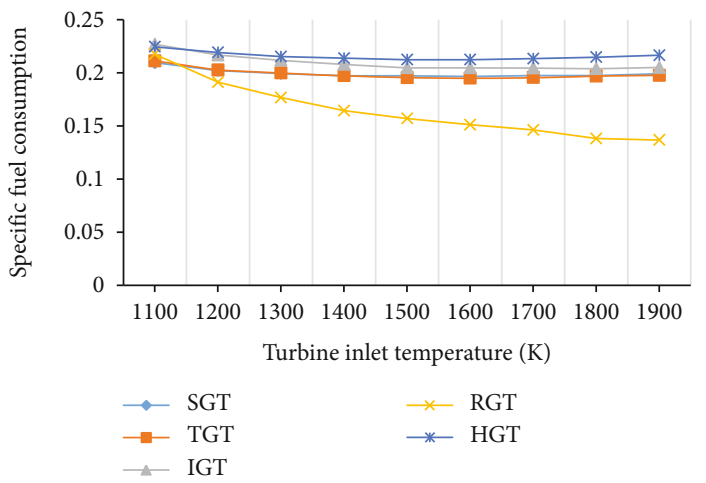

(c) Specific fuel consumption

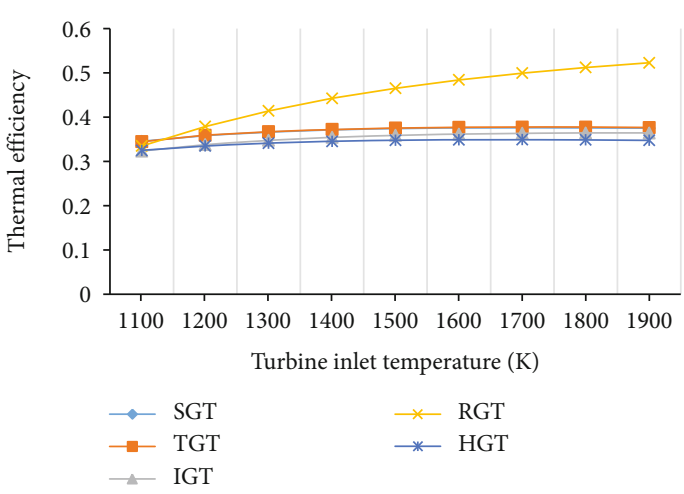

(b) Thermal efficiency

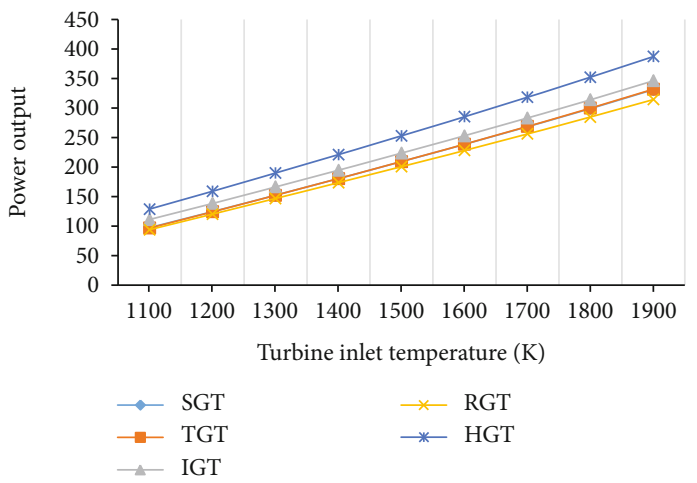

(d) Power output

FIgURE 9: The impact of the TIT on the performance of the gas-turbine.

regenerative GT, there is an increase in the thermal efficiency of about $3.1 \%$ in all the configurations, while for the regenerative GT configuration, the thermal efficiency increased from 33.4 to $52.3 \%$. Furthermore, the effect of the TIT on the specific fuel consumption of the GT plant for different configurations is shown in Figure 9(c). The specific fuel consumption decreases from 0.218 to $0.137 \mathrm{~kJ} / \mathrm{kWh}$ with the increase of the TIT for all configurations, except for the regenerative GT which reduced by about $0.01 \mathrm{~kJ} / \mathrm{kWh}$. Figure 9(a) shows the variation of output power versus TIT. As is evident, the increment in the TIT leads to an increase in the output power. But the TIT is significant at the higher values on the output power variation. Due to the burning of more fuel in the additional combustion chamber, the output power obtained in the reheated GT configuration is higher [47]. The less the fuel burned in the combustion chamber of the regenerative GT, the lower the output power obtained in this configuration which is consistent with the results of Figure $9(\mathrm{~d})$.

The effect of the isentropic compressor efficiency $\left(C_{\text {eff }}\right)$ on the performance of the GT plants is shown in Figure 10. The variation of the exhaust temperature of the GT with the $C_{\text {eff }}$ for different configurations is demonstrated in Figure 10(b). In the case of all the configurations, except the regenerative GT configuration, at a constant TIT, there is no evident effect of the exhaust temperature on the $C_{\text {eff }}$. This occurs since the exhaust temperature is a function of the TIT [54], while the rise in the $C_{\text {eff }}$ leads to a decrease in the exhaust temperature from 780 to $631 \mathrm{~K}$ for the regenerative GT configuration. The effect of this isentropic efficiency on the thermal efficiency for different configurations of the GT plant is depicted in Figure 10(a). Increasing the $C_{\text {eff }}$ leads to an increase in thermal efficiency. According to [35], reducing the thermal loss in the compressor increases the output power and thermal efficiency. At the maximum $C_{\text {eff }}$, it is noticed that the lowest thermal efficiency of $36.8 \%$ occurs in the case of the reheated GT configuration, whereas the highest thermal efficiency of $52.3 \%$ occurs in the case of regenerative GT configuration. Moreover, a deviation in the thermal efficiency of the highest $C_{\text {eff }}$ is observed, while an insignificant deviation in this efficiency is obtained at the lowest $C_{\text {eff }}$. The variation of specific fuel consumption and $C_{\text {eff }}$ for various GT configurations is shown in Figure 10(b). For all the configurations, the specific fuel consumption decreases with the increase in the $C_{\text {eff }}$, which can be attributed to the decline in compressor losses [40, 55]. At the regenerative GT configuration, the lowest specific fuel consumption of $0.14 \mathrm{~kg} / \mathrm{kWh}$ is noted, while at the reheated GT configuration, the highest specific fuel consumption is $0.2 \mathrm{~kg} / \mathrm{kWh}$. Further, the effect of the $C_{\text {eff }}$ on the output power for different configurations is exhibited in Figure 10(a). In the case of all the configurations, the rise in the $C_{\text {eff }}$ leads to an increase in the output power which is due to the reduction in energy losses in the compressor of the GT [56]. At the maximum $C_{\text {eff }}$, although the lowest output power $(200 \mathrm{MW})$ occurs in the regenerative GT, the 


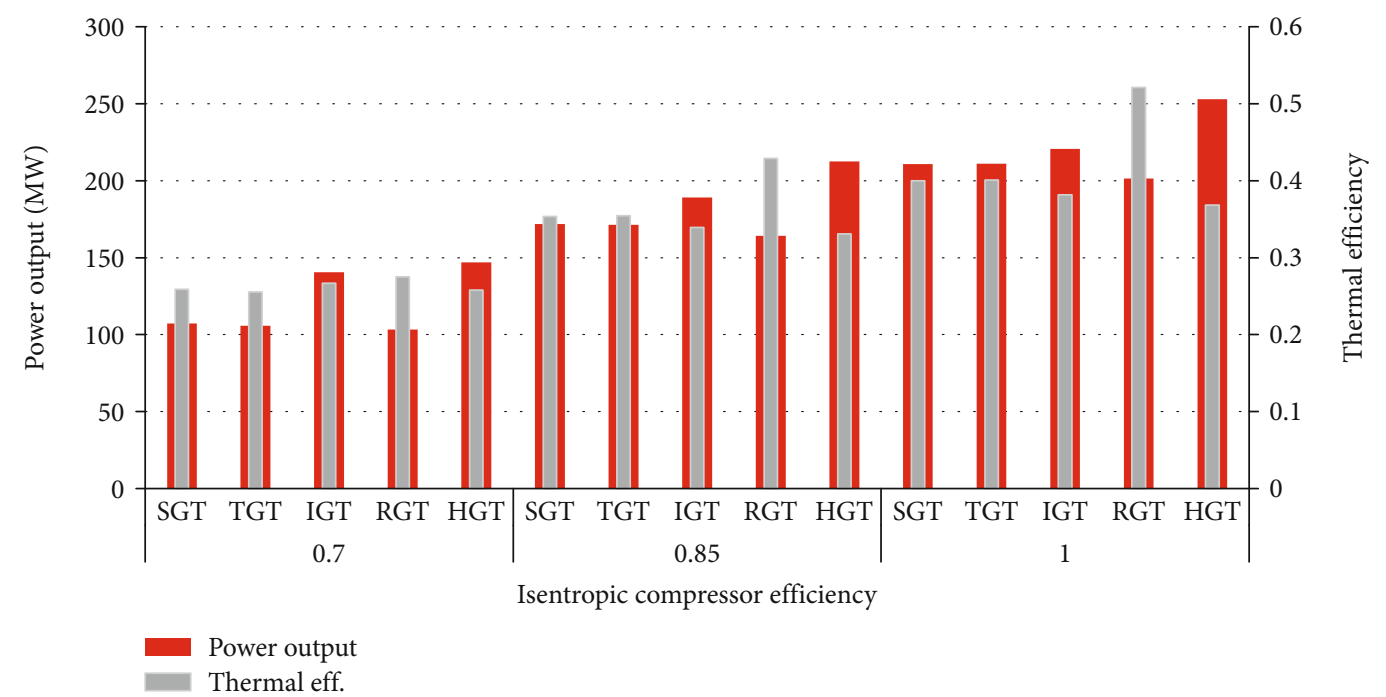

(a)

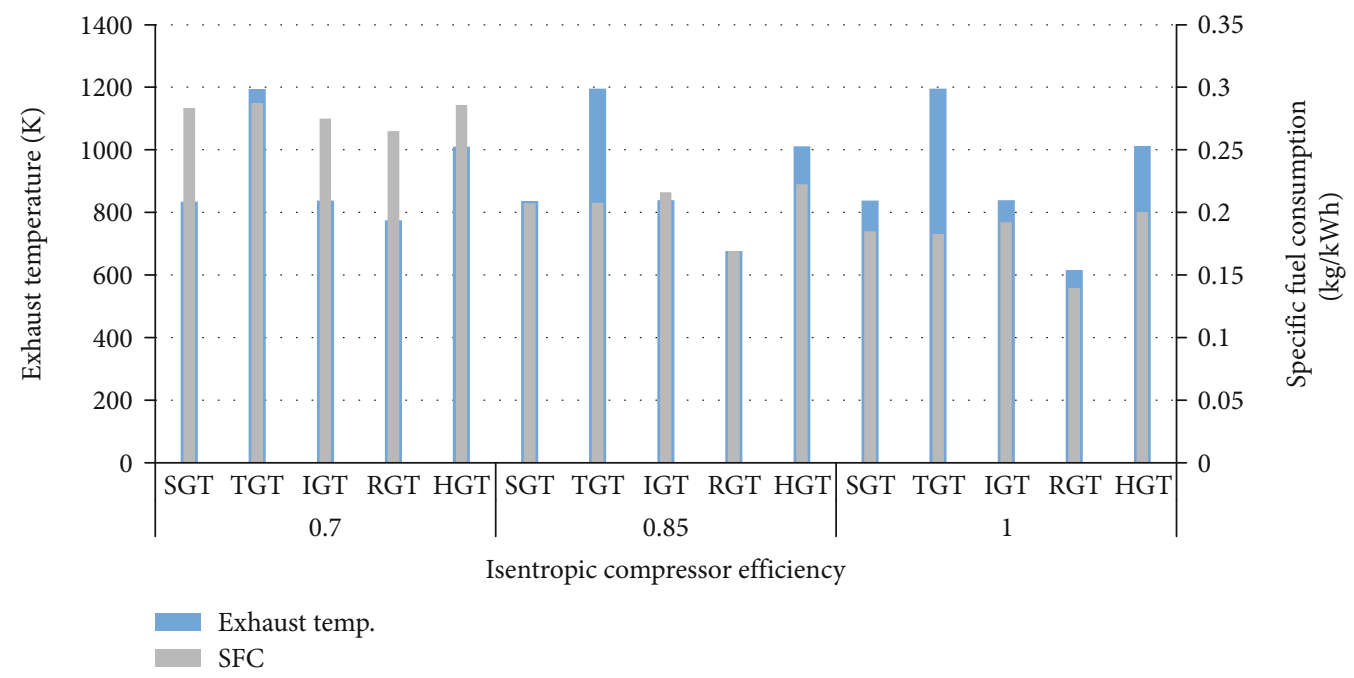

(b)

Figure 10: The impact of the isentropic compressor efficiency $\left(C_{\text {eff }}\right)$ on the performance of the gas-turbine.

highest output power (about $253 \mathrm{MW}$ ) occurs in the reheated GT.

The effect of the isentropic turbine efficiency $\left(T_{\text {eff }}\right)$ on the performance of the GT plants is shown in Figure 11. The effect of this isentropic efficiency on the exhaust temperature for different configurations is displayed in Figure 11(b). For all the configurations, increasing the $T_{\text {eff }}$ leads to a decrease in the exhaust temperature. This is because of the conversion of the extra heat from the exhaust gases to create more useful power with the increase of the $T_{\text {eff }}$ [36]. The two-shaft GT has the highest exhaust temperature of $1251 \mathrm{~K}$, while the lowest exhaust temperature of $665 \mathrm{~K}$ is obtained in the regenerative GT. In addition, the variation of the thermal efficiency with the $T_{\text {eff }}$ of different GT configurations is shown in Figure 11(a). There is an apparent increase in the thermal efficiency of all the configurations with the increase in the $T_{\text {eff }}$. The increased work done by the turbine of the GT plant is the reason behind it [57]. The regenerative GT has the highest thermal efficiency of $50.8 \%$ at the maximum $T_{\text {eff }}$. Similar trends were observed for the thermal efficiency of other configurations of the GT; however, the low energy losses with the exhaust gases resulted in this high value of thermal efficiency for the regenerative model. Therefore, the thermal efficiency is incredibly significant at higher isentropic turbine efficiency of the GT plants. Furthermore, the effect of the $T_{\text {eff }}$ on the specific fuel consumption for different configurations is represented in Figure 11(b).

As the $T_{\text {eff }}$ increases, the specific fuel consumption decreases. It should be mentioned here that at a constant TIT, the output power is increased with the increase in the $T_{\text {eff }}$ [36]. Thus, under the effect of these parameters, the specific fuel consumption is reduced. At the maximum $T_{\text {eff }}$, the regenerative GT has the lower specific fuel consumption of $0.145 \mathrm{~kg} / \mathrm{kWh}$ since more heat energy is recovered from the exhaust gases. This leads to a reduction in fuel consumption in the case of the regenerative GT configuration. Similar 


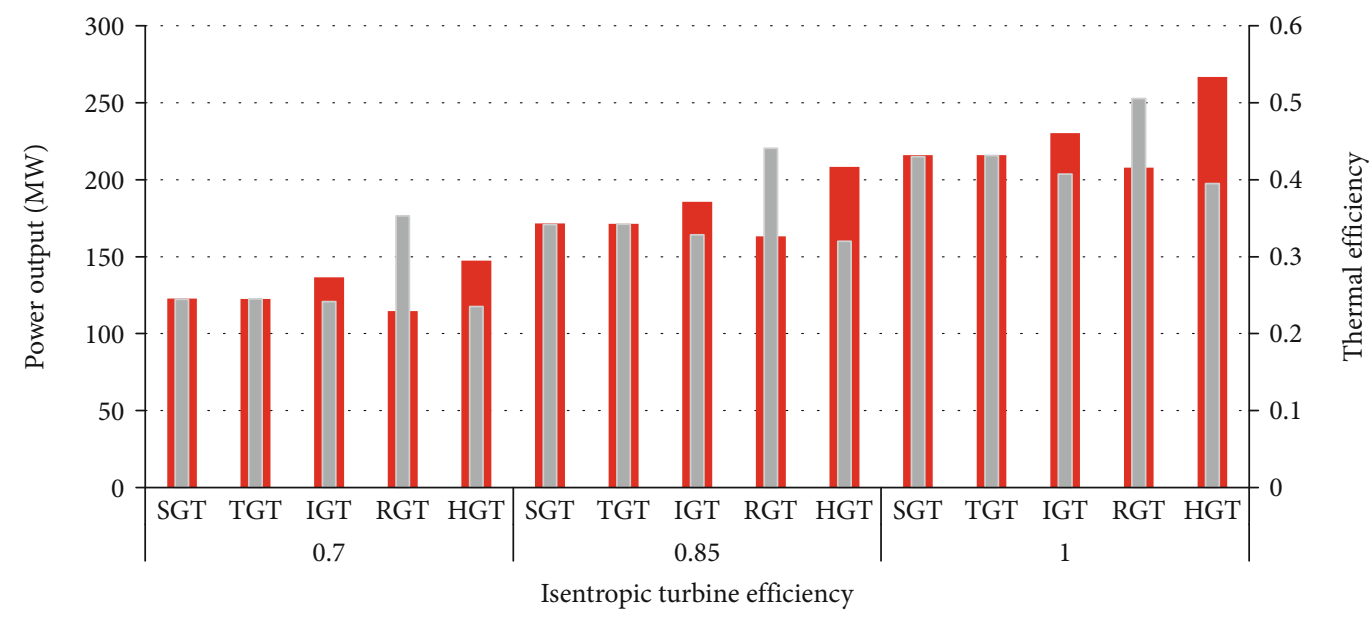

(a)

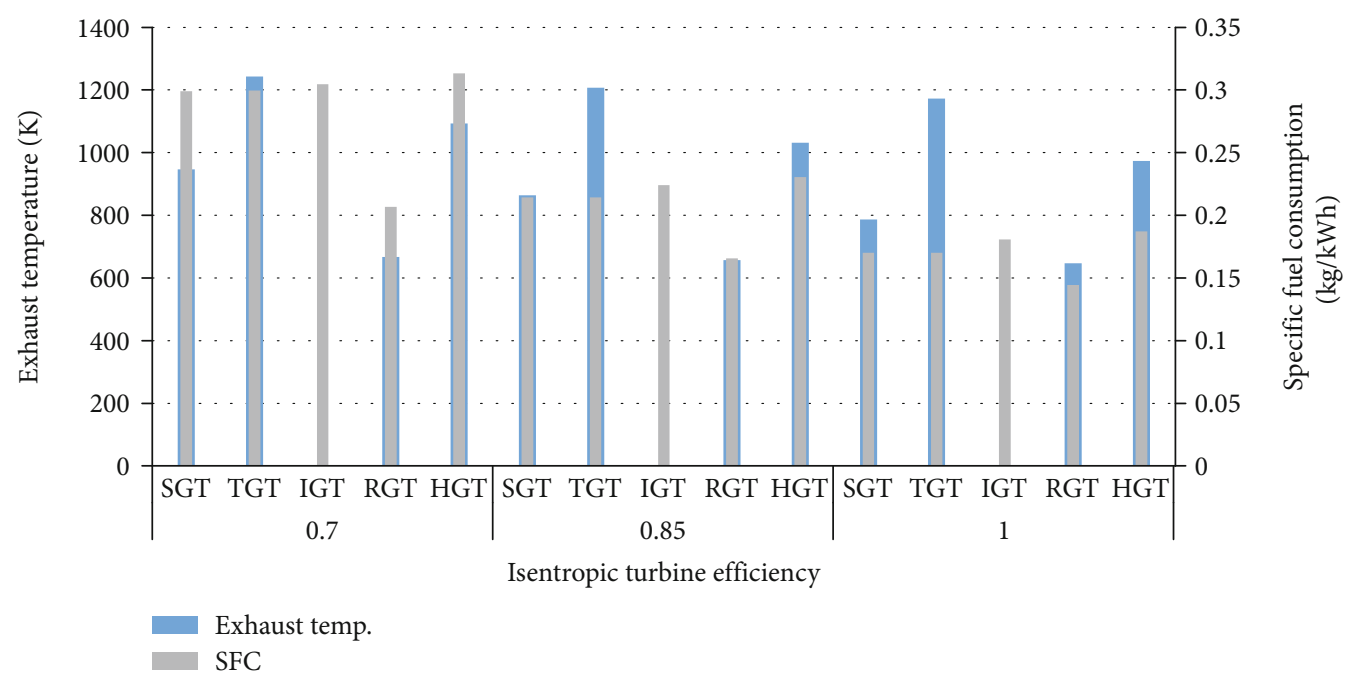

(b)

FIGURE 11: The impact of the isentropic turbine efficiency $\left(T_{\text {eff }}\right)$ on the performance of the gas-turbine.

behavior has been observed for the other GT configurations. Figure 11(a) shows the variation of the output power with the $T_{\text {eff }}$ for different configurations of the GT. It is observed that increasing the $T_{\text {eff }}$ linearly increases the output power. The variations in the output power are significant at the highest isentropic turbine efficiency.

Since fewer fuel burns in the combustion chamber of the regenerative model, the lowest output power is obtained in this configuration. On the other hand, although there is more fuel burned in the additional combustion chamber as shown in Figure 11(a), the highest output power (268 MW, at the maximum $T_{\text {eff }}$ ) is achieved in the reheated GT configuration. Therefore, in the case of the huge $T_{\text {eff }}$ of the GT plants, there is significant output power. According to the trends described in the previous studies, the validity of our models and their foregoing results has been strongly emphasized [56].

4.2. Optimization Techniques. In this section, an optimization of the ANFIS model structure utilizing the actual data
TABLE 1: Training error of different MFs.

\begin{tabular}{lcc}
\hline \multirow{2}{*}{ Membership function (MF) } & \multicolumn{2}{c}{ RMSE output MF type } \\
& Constant & Linear \\
\hline Product sigmoidal (psigmf) & 0.08071 & 0.004006 \\
Difference sigmoidal (dsigmf) & 0.152021 & 0.0050048 \\
Pi curve (pimf) & 0.122082 & 0.0091116 \\
Gaussian (gaussmf) & 0.011867 & 0.00017438 \\
Gaussian 2 (gauss2mf) & 0.050265 & 0.0022592 \\
Generalized bell (gbellmf) & 0.076138 & 0.0033531 \\
Trapezoidal (trapmf) & 0.258162 & 0.0098235 \\
Triangular (trimf) & 0.08071 & 0.004005 \\
\hline
\end{tabular}

of the best simulation cases is shown (from the Baiji GasTurbines in Iraq). A total of 420 samples from both real field experimental and simulation data used for training and testing the ANFIS model are utilized. The experimental data 


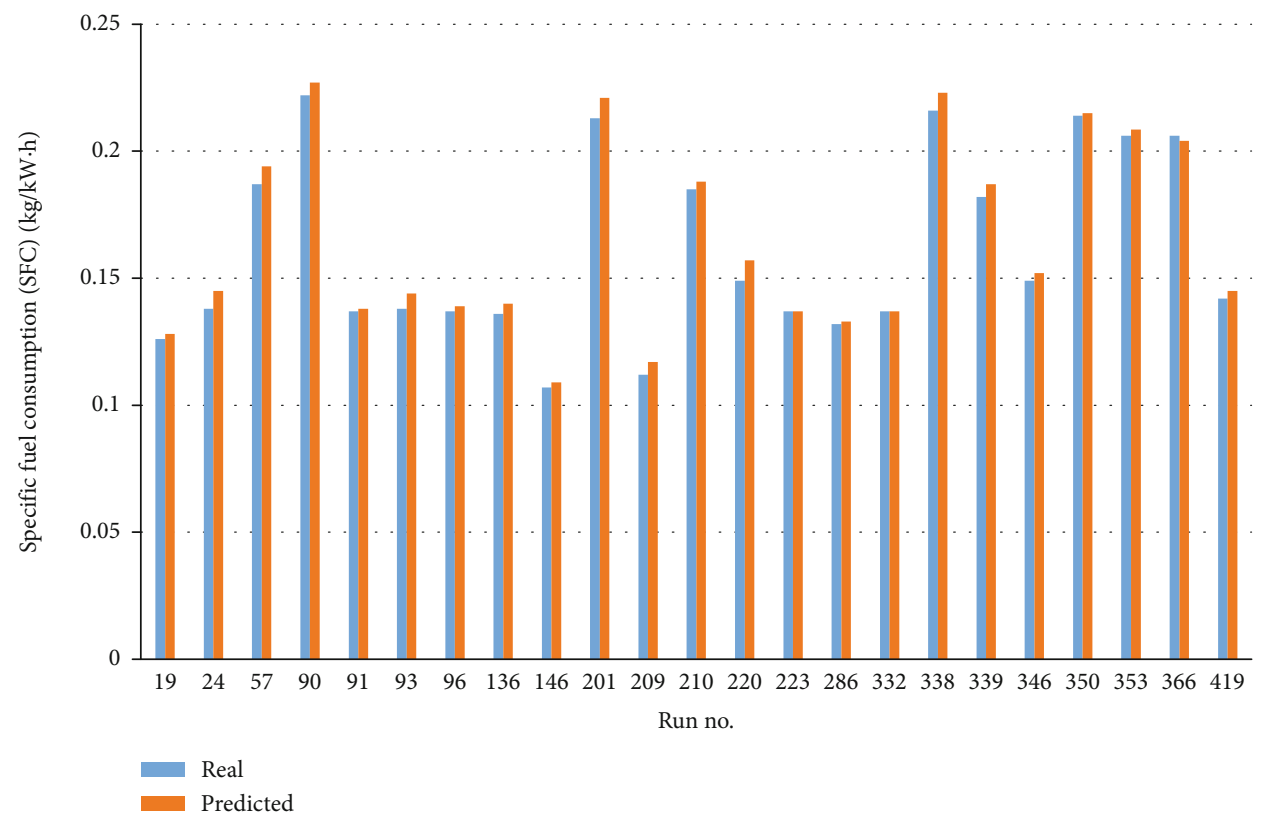

(a) Specific fuel consumption (SFC)

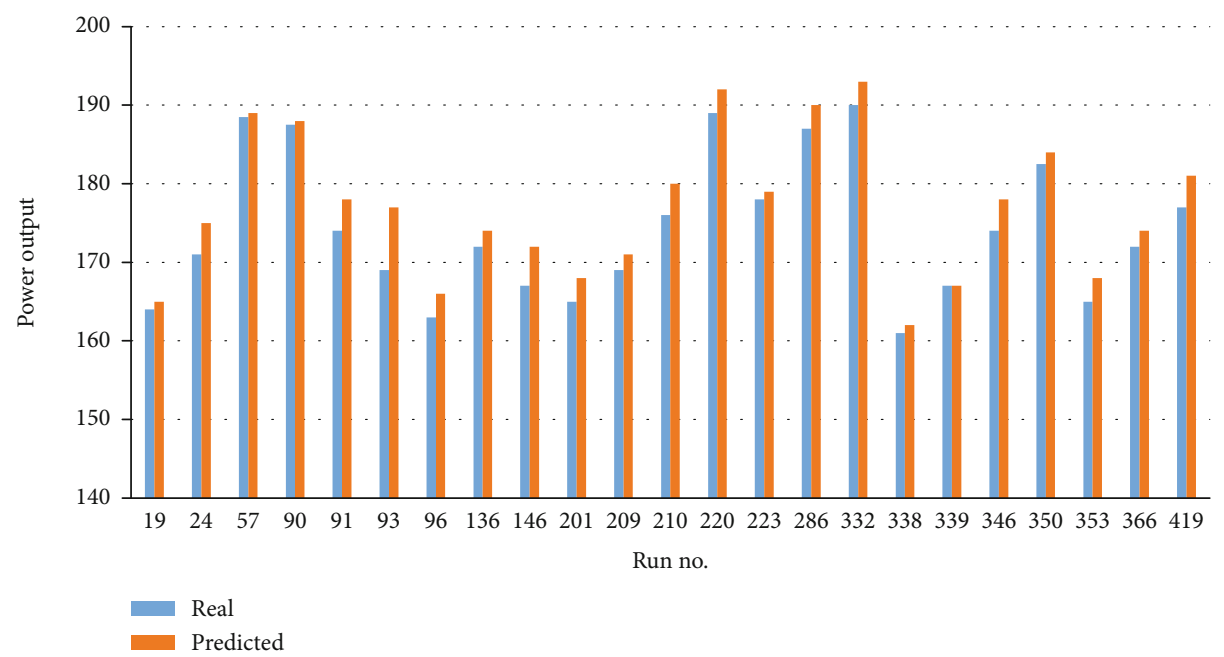

(b) Power output

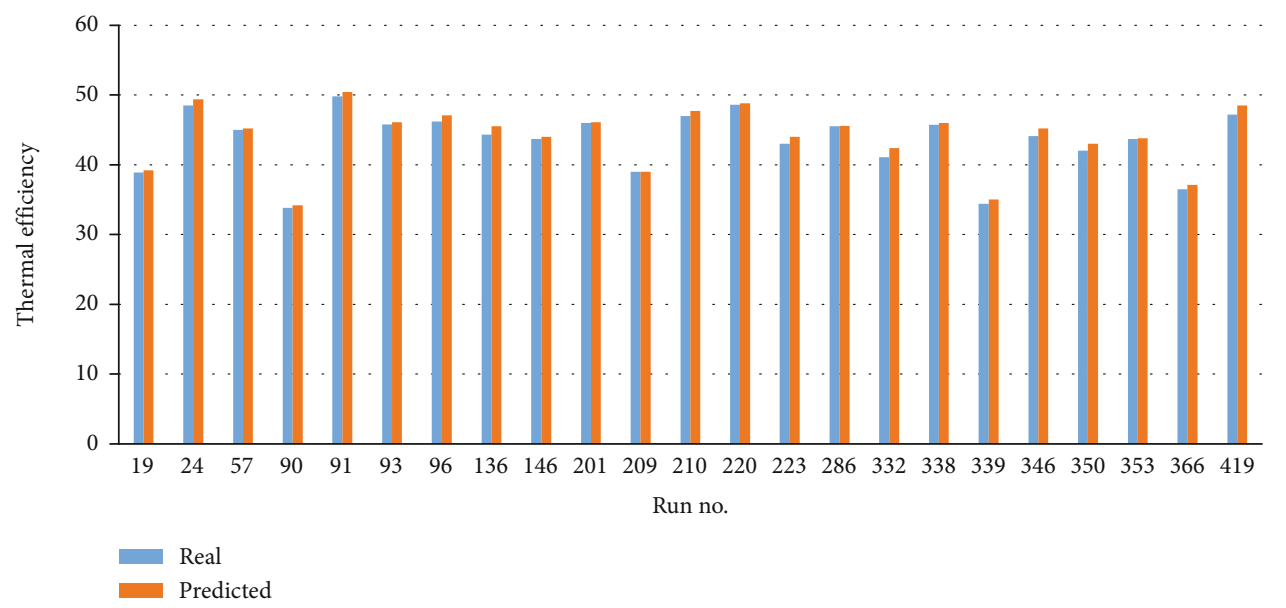

(c) Thermal efficiency

FIGURE 12: The comparison between the real and predicted data using the ANFIS model. 
were divided into two groups in which $85 \%$ is used for training and the remainder for testing the performance of the fuzzy inference model.

Table 1 summarizes the convergence characteristics of the constant and linear outputs for eight different membership functions in which the linear function shows less RMSE compared to the other membership function for the three model outputs.

Figure 12 compares the actual data and the optimum predicted outputs of the SFC, output power, and thermal efficiency. It is clear that the deviation between the actual and predicted data is very low. That is, the maximum deviations are about $4.8 \%, 2.51 \%$, and $2.91 \%$ for SFC, output power, and thermal efficiency, respectively.

The root-mean-square error (RMSE) parameter for testing the ANFIS model on the whole set of test data in the calculation of the respective output (exhaust temperature, specific fuel consumption (SFC), power output, and thermal efficiency) is shown as follows [28]:

$$
\operatorname{RMSE}_{j}=\sqrt{\frac{1}{n_{\text {patt }}} \sum_{i=1}^{n_{\text {patt }}}\left(\frac{O_{i}-y_{i}}{O_{i}}\right)^{2}} \quad j=1, \cdots, n_{S}
$$

where $O_{i}$ is the target outputs, $\mathrm{y}_{i}$ is the computed outputs, $n_{\text {patt }}$ is the pattern numbers used for testing the ANFIS model, and $n_{S}$ is the number of the sample in each pattern.

Therefore, the result is represented in Figure 13, which demonstrates the comparison of the root-mean-square error (RMSE) of the testing parameters between the predicted and actual plant data. Meanwhile, the maximum error that occurred with the power output was about $3.2 \%$ at sample no. 4. Also, the minimum error that appeared with the thermal efficiency was about $0.44 \%$. Therefore, the results show that the ANFIS model showed superior prediction for the performance of the Baiji Gas-Turbine power plant.

Furthermore, Figure 14 demonstrates the optimum performance of the regenerative GT based on the ANFIS model to select the optimal parameters for the Baiji Gas-Turbine power plant. The effect of the TIT and the $C_{\text {eff }}$ on thermal efficiency is shown in Figure 14(a). It is noticed that the thermal efficiency decreased with increasing TIT at low $C_{\text {eff }}$ . This may be due to the increased fuel consumption, which subsequently leads to an increase in the TIT [19]. The peak thermal efficiency obtained is about $63 \%$ when the TIT and the $C_{\text {eff }}$ are $1900 \mathrm{~K}$ and $100 \%$, respectively. Figure $13(\mathrm{~b})$ depicts the output power, which is affected by the TIT and the $C_{\text {eff }}$. It is apparent that the power is increased when both the TIT and the $C_{\text {eff }}$ are increased [58]. The maximum output power is about $375 \mathrm{MW}$ at the same aforesaid maximum values of the TIT and the $C_{\text {eff }}$. Furthermore, the variation of the specific fuel consumption with the selected optimum parameters is described in Figure 13(c). It is noted that the drop in fuel consumption occurs when increasing both the pressure ratio and the isentropic turbine efficiency. This behavior stems from the fact that the losses of the GT reduce with the increase of the isentropic turbine efficiency $\left(T_{\text {eff }}\right)$, and then the output power increases at a constant TIT; thus,

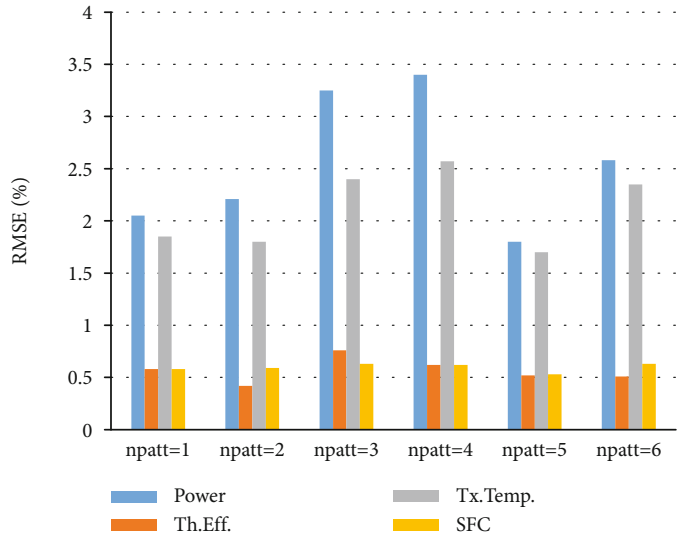

Figure 13: The RMSE for comparison of predicted and experimental performance data.

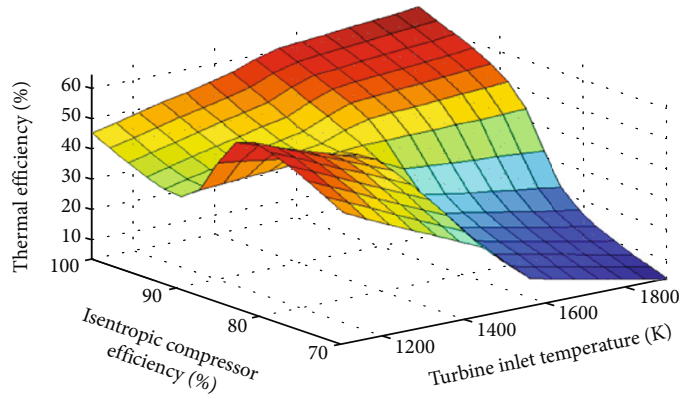

(a)

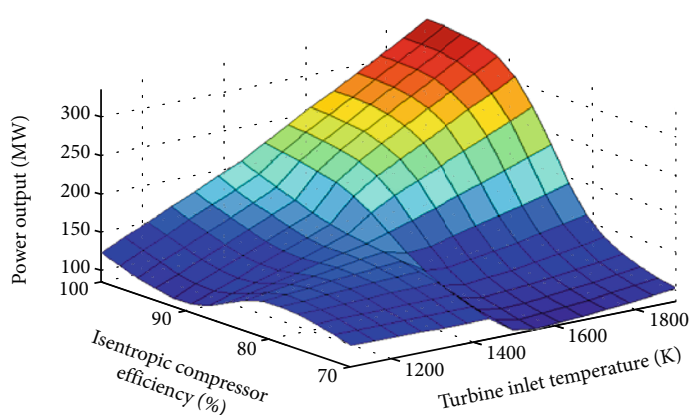

(b)

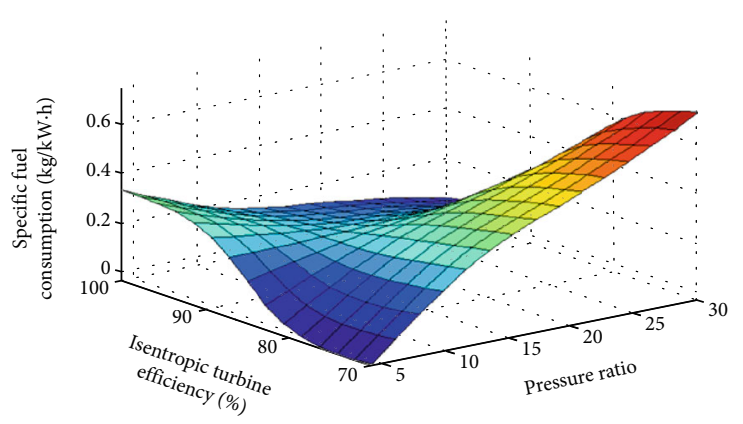

(c)

FIgURE 14: Predicted performance of the RGT with optimum parameters: (a) thermal efficiency, (b) power, and (c) specific fuel consumption. 
the specific fuel consumption decreases [59]. Hence, the optimum value of the specific fuel consumption is about $0.033 \mathrm{~kg} / \mathrm{kWh}$, when the pressure ratio and the isentropic turbine efficiency are 30 and 100\%, respectively. Good agreement can be seen with the results of the previous studies [59].

\section{Conclusion}

Several configurations of the gas-turbine cycle have been assessed with the influence of some operational parameters, including the isentropic turbine efficiency, ambient temperature, turbine inlet temperature, isentropic compressor efficiency, and pressure ratio. Moreover, the proposed ANFIS model improves the performance of the gas-turbine cycle and leads to the following conclusions, as well:

(1) The structure of the ANFIS model shows accurate enough outcomes to predict the SFC, power, and thermal efficiency, with the triangular MF and the linear output MF, and achieve the best results

(2) The pressure ratio, ambient temperature, and isentropic turbine efficiency strongly influence the predicted model results

(3) The conjunction of the ANFIS model with the regenerative GT offers superior performance compared to that of the actual power plant

\section{Abbreviations}

ANFIS: Adaptive neuro-fuzzy inference system

$T_{\text {eff }}: \quad$ Isentropic turbine efficiency

$C_{\text {eff }}$ : Isentropic compressor efficiency

TIT: Turbine inlet temperature

RGT: Regenerative gas-turbine

SFC: $\quad$ Specific fuel consumption

HGT: Reheat gas-turbine

CHP: Combined heat and power

CCGT: Combined cycle gas-turbine

GT: $\quad$ Gas-turbines

HRSG: Heat recovery steam generator

$W_{\text {Gnet }}$ : Work net of the gas-turbine

$P: \quad$ Turbine output power

TGT: Two-shaft gas-turbine

IGT: Intercooled gas-turbine.

Symbols

$\eta_{m}: \quad$ Mechanical efficiency

$\eta_{g}: \quad$ Generator efficiency

$\eta_{c}: \quad$ Isentropic compressor efficiency

$\eta_{t:}: \quad$ Isentropic turbine efficiency

$\eta_{t h}: \quad$ Gas-turbine thermal efficiency

$\dot{m}_{g}$ : Gases mass flow rate

$\dot{m}_{a}$ : $\quad$ Mass flow rate of inlet air

$\dot{m}_{f}$ : $\quad$ Mass flow rate of fuel

$T_{5 s}$ : $\quad$ Exit low-pressure turbine temperature

$C_{p a}: \quad$ Specific heat of air

$C_{p g}: \quad$ The specific heat of flue gas $(\mathrm{kJ} / \mathrm{kg} \cdot \mathrm{K})$ $\varepsilon: \quad$ Effectiveness of the regenerative heat exchanger

$x$ and $y$ : Adaptive model inputs

$f: \quad$ Adaptive model output

$O_{\mathrm{n}, \mathrm{i}}: \quad$ Presented layer output node

$f_{r}: \quad$ Fuel-to-air ratio

$r_{p}: \quad$ Pressure ratio

$\gamma_{g}$ : Specific heat ratio of gases

$\gamma_{a}: \quad$ Specific heat ratio of air

$Q_{\text {add }}: \quad$ Additional supplied heat

$T_{\mathrm{a}}: \quad$ Ambient temperature

$T_{1}$ : $\quad$ Ambient temperature

$T_{2}$ : $\quad$ Compressor outlet air temperature $(\mathrm{K})$

$T_{3}: \quad$ Turbine inlet temperature $(\mathrm{K})$

$T_{4}$ : $\quad$ Turbine exit temperature (K)

$T_{5}$ : $\quad$ Low gas-turbine exhaust gas temperature

$W: \quad$ Layer weight

$n$ : $\quad$ Layer number

$i$ : $\quad$ Node number in each layer.

\section{Data Availability}

Data available on request. For more information about that, you contact Dr. Ahmed N. Abdalla (dramaidecn@gmail.com).

\section{Conflicts of Interest}

The authors declare that they have no conflicts of interest.

\section{Acknowledgments}

The authors are grateful to the Science and Technology Research Project of Henan Province, Henan Polytechnic University, and Huaiyin Institute of Technology for providing financial support to complete this work (grant nos. 202102310560, JAS2018020, and JSLERS-2018-005).

\section{References}

[1] M. R. Salimpour, A. Ahmadzadeh, and A. T. Al-Sammarraie, "Comparative investigation on the exergoeconomic analysis of solar-driven ejector refrigeration systems," International Journal of Refrigeration, vol. 99, pp. 80-93, 2019.

[2] T. K. Ibrahim and M. M. Rahman, "Effect of compression ratio on the performance of different strategies for the gas turbine," International Journal of Automotive and Mechanical Engineering, vol. 9, pp. 1747-1757, 2014.

[3] F. Basrawi, T. K. Ibrahim, S. S. Sathiyaseelan, and A. A. Razak, "Experimental investigation on performance of solar-powered attic ventilation," in Sustainable Thermal Power Resources Through Future Engineering, pp. 1-19, Springer, 2019.

[4] A. Elghool, F. Basrawi, T. K. Ibrahim, K. Habib, H. Ibrahim, and D. M. N. D. Idris, "A review on heat sink for thermoelectric power generation: classifications and parameters affecting performance," Energy Conversion and Management, vol. 134, pp. 260-277, 2017.

[5] W. Zhang, T. Wang, S. Zheng, X. Peng, and X. Wang, "Experimental study of the gas engine driven heat pump with engine heat recovery," Mathematical Problems in Engineering, vol. 2015, Article ID 417432, 10 pages, 2015. 
[6] C. S. Antonio, G. C. David, R. A. Enrique, and B. P. JorgeJuan, "Technological improvements in energetic efficiency and sustainability in existing combined-cycle gas turbine (CCGT) power plants," Applied Energy, vol. 223, no. 1, pp. 30-51, 2018.

[7] R. Bartnik, Z. Buryn, and A. Hnydiuk-Stefan, "Methodology and mathematical model with the continuous time for the selection of the optimal power of the gas turbine set for the dual fuel gas-steam combined cycle in a parallel system," Applied Thermal Engineering, vol. 141, pp. 11611172, 2018.

[8] H. Barzegar Avval, P. Ahmadi, A. R. Ghaffarizadeh, and M. H. Saidi, "Thermo-economic-environmental multiobjective optimization of a gas turbine power plant with preheater using evolutionary algorithm," International Journal of Energy Research, vol. 35, no. 5, pp. 389-403, 2011.

[9] Z. Ge, F. Zhang, S. Sun, J. He, and X. Du, "Energy analysis of cascade heating with high back-pressure large-scale steam turbine," Energies, vol. 11, no. 1, p. 119, 2018.

[10] T. K. Ibrahim and M. M. Rahman, "Parametric simulation of triple-pressure reheat combined cycle: a case study," Advanced Science Letters, vol. 13, no. 1, pp. 263-268, 2012.

[11] A. Alahäivälä, J. Kiviluoma, J. Leino, and M. Lehtonen, "System-level value of a gas engine power plant in electricity and reserve production," Energies, vol. 10, no. 7, p. 983, 2017.

[12] L. Riboldi and L. Nord, "Lifetime assessment of combined cycles for cogeneration of power and heat in offshore oil and gas installations," Energies, vol. 10, no. 6, p. 744, 2017.

[13] T. K. Ibrahim and M. Rahman, "Effects of operation conditions on performance of a gas turbine power plant," in In Proceedings of National Conference in Mechanical Engineering Research and Postgraduate Studies (2nd NCMER 2010), pp. 135-144, Kuantan, Pahang, Malaysia, 2010.

[14] D. W. Wu and R. Z. Wang, "Combined cooling, heating and power: a review," Progress in Energy and Combustion Science, vol. 32, no. 5-6, pp. 459-495, 2006.

[15] G. Chicco and P. Mancarella, "Assessment of the greenhouse gas emissions from cogeneration and trigeneration systems. Part I: Models and indicators," Energy, vol. 33, no. 3, pp. 410-417, 2008.

[16] S. Wang, S. Wang, and J. Liu, "Life-cycle green-house gas emissions of onshore and offshore wind turbines," Journal of Cleaner Production, vol. 210, pp. 804-810, 2019.

[17] S. M. Tajalli and A. Tajalli, "Thermodynamic simulation of two-shaft gas turbine to study invasive weeds optimization and min-max controller strategies considering air-cooled blades," Journal of Mechanical Science and Technology, vol. 33, no. 2, pp. 931-938, 2019.

[18] H. Kurt, Z. Recebli, and E. Gedik, "Performance analysis of open cycle gas turbines," International Journal of Energy Research, vol. 33, no. 3, pp. 285-294, 2009.

[19] T. K. Ibrahim, M. Rahman, M. Mohammed, and F. Basrawi, "Statistical analysis and optimum performance of the gas turbine power plant," International Journal of Automotive and Mechanical Engineering, vol. 13, no. 1, p. 3215, 2016.

[20] W. D. Paepe, S. Abraham, P. Tsirikoglou, F. Contino, A. Parente, and G. Ghorbaniasl, "Operational optimization of a typical micro gas turbine," Energy Procedia, vol. 142, pp. 1653-1660, 2017.
[21] M. K. Sahu, “Thermoeconomic investigation of power utilities: intercooled recuperated gas turbine cycle featuring cooled turbine blades," Energy, vol. 138, pp. 490-499, 2017.

[22] J. Duan, L. Sun, G. Wang, and F. Wu, "Nonlinear modeling of regenerative cycle micro gas turbine," Energy, vol. 91, pp. 168175, 2015.

[23] Y. Yang, X. He, Y. Zhang, and D. Qin, "Regenerative braking compensatory control strategy considering CVT power loss for hybrid electric vehicles," Energies, vol. 11, no. 3, p. 497, 2018.

[24] A. Giusti, J. A. M. Sidey, G. Borghesi, and E. Mastorakos, "Simulations of droplet combustion under gas turbine conditions," Combustion and Flame, vol. 184, pp. 101-116, 2017.

[25] A. Lazzaretto and A. Toffolo, "Prediction of performance and emissions of a two-shaft gas turbine from experimental data," Applied Thermal Engineering, vol. 28, no. 17-18, pp. 24052415, 2008.

[26] Y. S. H. Najjar, "Comparison of performance for cogeneration systems using single- or twin-shaft gas turbine engines," Applied Thermal Engineering, vol. 17, no. 2, pp. 113-124, 1997.

[27] F. Basrawi, T. K. Ibrahim, K. Habib, and T. Yamada, "Effect of operation strategies on the economic and environmental performance of a micro gas turbine trigeneration system in a tropical region," Energy, vol. 97, pp. 262-272, 2016.

[28] K. S. Mithilesh, "Comparative exergoeconomics of power utilities: air-cooled gas turbine cycle and combined cycle configurations," Energy, vol. 139, pp. 42-51, 2017.

[29] L. Yang and E. Entchev, "Performance prediction of a hybrid microgeneration system using adaptive neuro-fuzzy inference system (ANFIS) technique," Applied Energy, vol. 134, pp. 197-203, 2014.

[30] J.-J. Wang, Y.-Y. Jing, and C.-F. Zhang, "Optimization of capacity and operation for CCHP system by genetic algorithm," Applied Energy, vol. 87, no. 4, pp. 1325-1335, 2010.

[31] R. Bettocchi, M. Pinelli, P. R. Spina, and M. Venturini, “Artificial intelligence for the diagnostics of gas turbines-part I: neural network approach," Journal of Engineering for Gas Turbines and Power, vol. 129, no. 3, pp. 711-719, 2007.

[32] R. Bettocchi, M. Pinelli, P. R. Spina, and M. Venturini, “Artificial intelligence for the diagnostics of gas turbines-part II: neuro-fuzzy approach," Journal of Engineering for Gas Turbines and Power, vol. 129, no. 3, pp. 720-729, 2007.

[33] Y.-K. Chan and J.-C. Gu, "Modeling of turbine cycles using a neuro-fuzzy based approach to predict turbine-generator output for nuclear power plants," Energies, vol. 5, no. 1, pp. 101-118, 2012.

[34] A. Rosato, R. Altilio, R. Araneo, and M. Panella, "Prediction in photovoltaic power by neural networks," Energies, vol. 10, no. 7, p. 1003, 2017.

[35] M. M. Rahman, T. K. Ibrahim, K. Kadirgama, R. Mamat, and R. A. Bakar, "Influence of operation conditions and ambient temperature on performance of gas turbine power plant," Advanced Materials Research, vol. 189-193, pp. 3007-3013, 2011.

[36] T. K. Ibrahim and M. M. Rahman, "Effects of isentropic efficiency and enhancing strategies on gas turbine performance," Journal of Mechanical Engineering and Sciences, vol. 4, pp. 383-396, 2013.

[37] F. Kreith and R. P. Chhabra, CRC Handbook of Thermal Engineering, CRC press, 2017. 
[38] M. Kumar, D. Panda, A. Kumar, R. K. Sahoo, and S. K. Behera, "A methodology for the performance prediction: flow field and thermal analysis of a helium turboexpander," Journal of the Brazilian Society of Mechanical Sciences and Engineering, vol. 41, no. 11, 2019.

[39] A. M. Alklaibi, M. N. Khan, and W. A. Khan, "Thermodynamic analysis of gas turbine with air bottoming cycle," Energy, vol. 107, pp. 603-611, 2016.

[40] T. K. Ibrahim and M. M. Rahman, "Optimum performance improvements of the combined cycle based on an intercooler-reheated gas turbine," Journal of Energy Resources Technology, vol. 137, no. 6, 2015.

[41] T. K. Ibrahim, M. Rahman, and A. N. A. Alla, "Study on the effective parameter of gas turbine model with intercooled compression process," Scientific Research and Essays, vol. 5, pp. 3760-3770, 2010.

[42] J.-S. R. Jang, "ANFIS: adaptive-network-based fuzzy inference system," IEEE Transactions on Systems, Man, and Cybernetics, vol. 23, no. 3, pp. 665-685, 1993.

[43] C. Chiu, W. Xian, and C. F. Moss, "Flying in silence: echolocating bats cease vocalizing to avoid sonar jamming," Proceedings of the National Academy of Sciences of the United States of America, vol. 105, no. 35, pp. 13116-13121, 2008.

[44] M. P. Boyce, Gas Turbine Engineering Handbook, Elsevier, 2011.

[45] A. M. Bassily, "Performance improvements of the intercooled reheat recuperated gas-turbine cycle using absorption inletcooling and evaporative after-cooling," Applied Energy, vol. 77, no. 3, pp. 249-272, 2004.

[46] K. Nishida, T. Takagi, and S. Kinoshita, "Regenerative steaminjection gas-turbine systems," Applied Energy, vol. 81, no. 3, pp. 231-246, 2005.

[47] R. Carapellucci and A. Milazzo, "Thermodynamic optimization of a reheat chemically recuperated gas turbine," Energy Conversion and Management, vol. 46, no. 18-19, pp. 29362953, 2005.

[48] L. Chen, B. Yang, and F. Sun, "Exergoeconomic performance optimization of an endoreversible intercooled regenerated Brayton cogeneration plant. Part 1: thermodynamic model and parameter analyses," International Journal of Energy and Environment, vol. 2, pp. 199-210, 2011.

[49] T. Nada, "Performance characterization of different configurations of gas turbine engines," Propulsion and Power Research, vol. 3, no. 3, pp. 121-132, 2014.

[50] S. Peng, H. Hong, H. Jin, and Z. Wang, "An integrated solar thermal power system using intercooled gas turbine and Kalina cycle," Energy, vol. 44, no. 1, pp. 732-740, 2012.

[51] T. K. Ibrahim and M. N. Mohammed, "Thermodynamic evaluation of the performance of a combined cycle power plant," International Journal of Energy Science and Engineering, vol. 1, p. 11, 2015.

[52] W.-J. Yang, "Reduction of specific fuel consumption in gas turbine power plants," Energy Conversion and Management, vol. 38, no. 10-13, pp. 1219-1224, 1997.

[53] A. De Sa and S. Al Zubaidy, "Gas turbine performance at varying ambient temperature," Applied Thermal Engineering, vol. 31, no. 14-15, pp. 2735-2739, 2011.

[54] P. A. Dellenback, "Improved gas turbine efficiency through alternative regenerator configuration," Journal of Engineering for Gas Turbines and Power, vol. 124, no. 3, pp. 441-446, 2002.
[55] M. Farzaneh-Gord and M. Deymi-Dashtebayaz, "A new approach for enhancing performance of a gas turbine (case study: Khangiran refinery)," Applied Energy, vol. 86, no. 12, pp. 2750-2759, 2009.

[56] T. K. Ibrahim, M. K. Mohammed, O. I. Awad et al., "The optimum performance of the combined cycle power plant: a comprehensive review," Renewable and Sustainable Energy Reviews, vol. 79, pp. 459-474, 2017.

[57] M. Rahman, T. K. Ibrahim, and A. N. Abdalla, "Thermodynamic performance analysis of gas-turbine power-plant," International Journal of Physical Sciences, vol. 6, pp. 35393550, 2011.

[58] M. A. A. Alfellag, "Parametric investigation of a modified gas turbine power plant," Thermal Science and Engineering Progress, vol. 3, pp. 141-149, 2017.

[59] S. Ramakrishnan and C. F. Edwards, "Maximum-efficiency architectures for heat- and work-regenerative gas turbine engines," Energy, vol. 100, pp. 115-128, 2016. 